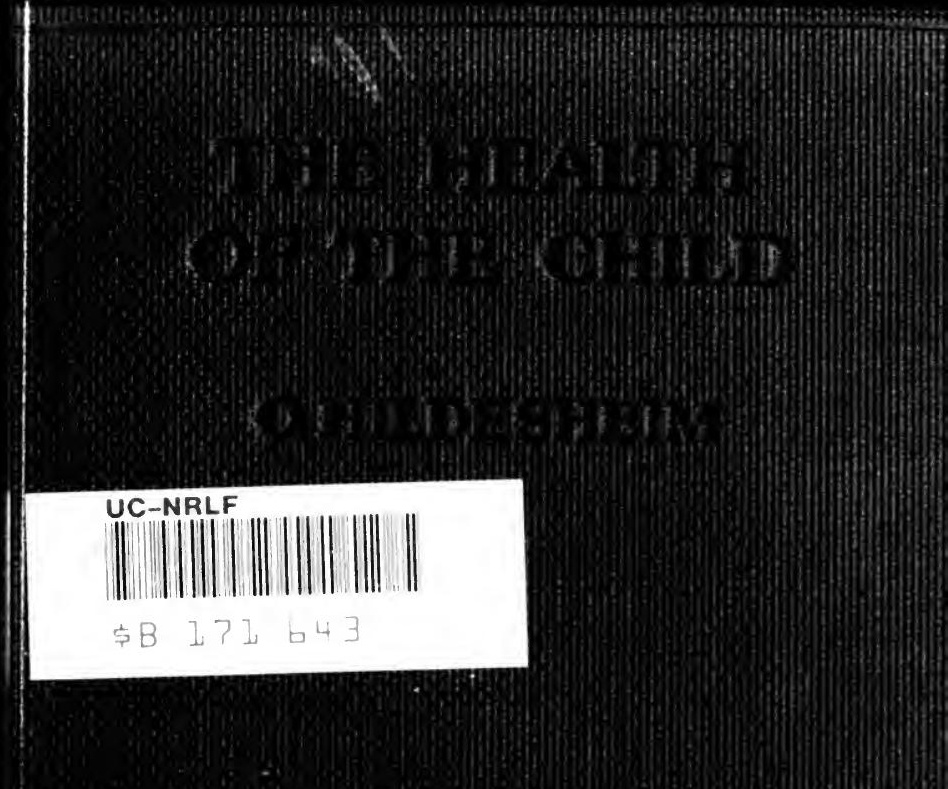



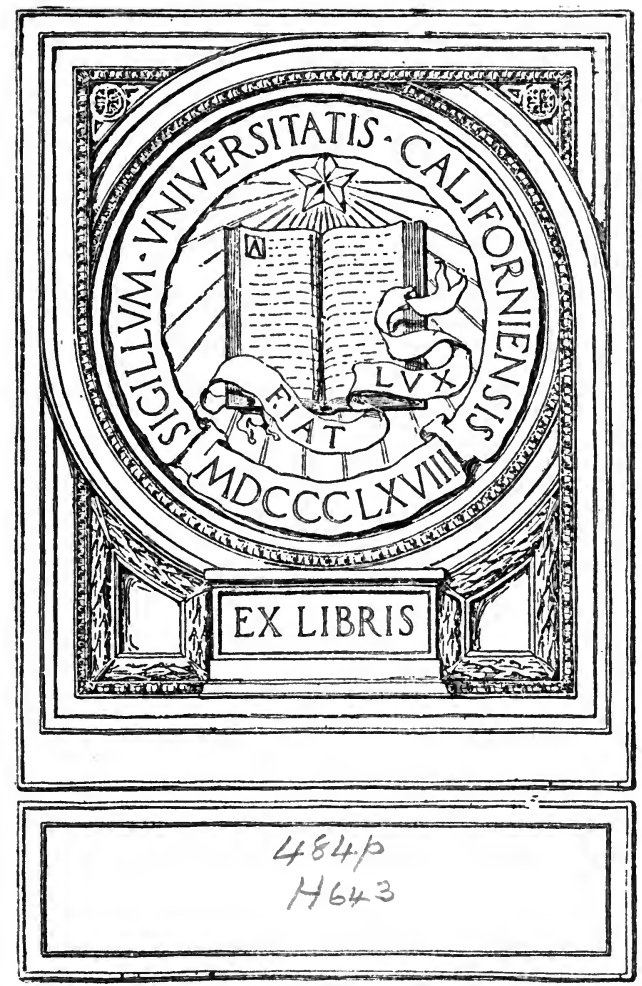
Digitized by the Internet Archive in 2007 with funding from Microsoft Corporation 



\section{THE HEALTH OF THE CHILD}





\title{
THE HEALTH OF THE CHILD
}

A MANUAL FOR MOTHERS AND NURSES

\author{
BY \\ O. H I L D E S H E I M \\ M.D., B.CH. OXON. \\ Late House Physician, Hospital for Sick Children \\ Great Ormond Street

\begin{abstract}
WITH AN INTRODUCTION BY
G E O R G F R E D E R I C S T ILL
\end{abstract} \\ M.A., M.D. (CANTAB.), F.R.C.P. (LONDON) \\ Professor of Diseases of Children, King's College, London \\ Physician to Out-patients, Hospital for Sick Children \\ Great Orinond Street
}

NEW YORK

FREDERICK A. STOKES COMPANY

PUBLISHERS 
$x^{1}$

BIOLOA 
TO

JOHN, ROGER AND MICHAEL 
'We should be showing ourselves less generous than the cave-men, if, now that our turn has come, we did not strive to make life better and more secure for our children than it is for ourselves. To achieve this end, two things are indispensable, knowledge and love; for with knowledge and love the world is made.'-My Friend's Book.

anatole France. 


\section{INTRODUCTION}

I SUPPOSE there is no great undertaking 1 in life that is more commonly approached without training or forethought than the upbringing of children. I am speaking of their physical care, and surely it is a great undertaking. The future of a nation lies with its children, and the future of its children is bound up with their health.

It has been the custom to assume that any woman can tend the rearing of a child, an assumption which implies either that the proper care of children requires no special knowledge at all, or that this knowledge is somehow present in women as a matter of instinct.

The lower animals, it is true, are guided by instinct in caring for their young, but in the course of evolution, social and otherwise, 


\section{viii THE HEALTH OF THE CHILD}

man, homo sapiens, has travelled so far from the ways of nature that natural instinct is no longer a safe guide. Evolution has produced not only the upright position, and the prehensile digit, but also the modern milkman and the patent food, and many another complication which adds danger and perplexity to the care of the young.

The need for instruction grows more instead of less as civilisation advances and the complexity of modern life increases, for, not only are there introduced dangers and difficulties, appertaining to artificial ways of life, but at the period when most an infant should receive from its mother the nourishment which above all others lays the foundation of a sound and healthy constitution, this is becoming less and less often possible of attainment. The reasons for this are twofold, the exigencies of modern social life which intervene increasingly between mother and child, and, a fact of sinister outlook, the diminishing capacity for suckling which seems to be one of the penalties of present day conditions. 
Nevertheless, a wisely directed teaching may do much to safeguard the period of infancy and childhood. Ignorance even more than disability is responsible for the heavy mortality in infancy, and for much preventable disease in early life.

Already there are signs that the haphazard method, or rather lack of method, which has prevailed in the rearing of children, especially amongst the poor, is giving place to something better. Infant Consultations and Schools for Mothers are teaching the essentials of childcare, and those of us who have seen the undoubted improvement resulting from the less directly educational work of the out-patient departments in children's hospitals will be most sanguine of the outcome.

To the rearing of a healthy child there needs no complex system of theory, but only the knowledge and practice of simple rules of health. These it has been the purpose of Dr. Hildesheim to inculcate, and he has done so with a clearness and conciseness which will make his teaching doubly valuable to all who 


\section{$x$ THE HEALTH OF THE CHILD}

are interested in the physical welfare of children. If as sponsor to his book I present it without further praise, it is because I feel sure the book itself will prove its own best recommendation.

G. F. STILL

March I9I5 


\section{CONTENTS}

INTRODUCTION by G. F. STILL, M.D., F.R.C.P., . . . . . . . vii FOREWORD, . . . . . . . . . $\quad$ I

I. Growth and Development, . . . 3 Changes at Birth, - . . . . . . 3

Peculiarities of the Infant, . . . . . 4

Other differences between the Child and the Adult, . . . . . . 6

Mental Development, . . . . 7

Weight, . . $\quad$. $\quad . \quad$. 7

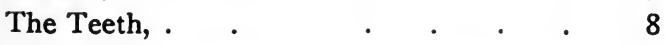

II. The Health of the Child before Birth, I4

III. FOOd AND FEeding, . $\quad$. $\quad$. $\quad$. $\quad$. 17

Advantages of Human Milk, . . . $\quad 18$

Causes for Hand-feeding, . $\quad$. $\quad$. $\quad$. $\quad 19$

Details of Breast-feeding, . . . . 22

Hand-feeding, · . . . . . 24

Faults of Hand-feeding, . . . . 30 


\section{xii THE HEALTH OF THE CHILD}

Patent Foods, . . . . . . . . 34

Diet from 9 months to 2 years, . . . 37

Diet from 2 years to 4 years, . . . 39

Diet of older children, . . . . 40

Constipation, . . . . . . . 45

Diarrhoea, . . . . . . . . 48

IV. Hygiene of The Nursery, . . . 5 I

Washing, • . . . . . . $5 \mathrm{I}$

Clothing, . . . . . . . 54

The Nursery, . . . . . . 56

Exercise, . . . . . . . 58

Rest, . . . . . . . . $6 \mathrm{I}$

Fresh Air, . . . . . . . . 62

Chill, . . . . . . . . . . 64

Mouth Breathing, . . . . . 66

V. ThE Sick CHILd, . . . . . $7 \mathrm{I}$

When to send for the Doctor, . . . 7 I

Common Complaints, . • . . . 75

Home Nursing and Household Remedies . $\quad 8_{3}$

Infectious Diseases of Childhood, . . 9 I

Emergencies, • • • • • . 96

VI. Training The Child, . . . . . IOI

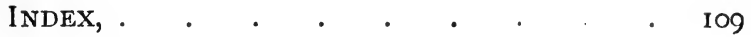




\section{THE HEALTH OF THE CHILD}

\section{FOREWORD}

CLEANLINESS is the key-note of success in the proper care of the health of the individual, as it is in the care of the health of the nation.

The achievements of modern surgery have been made possible almost entirely by the scientific appreciation of the significance of cleanliness. The same is true, to a large extent, of modern medicine as illustrated for example by the medical triumphs which made it possible to construct the Panama Canal. The old definition of dirt is matter misplaced. But from the scientific point of view, a better definition might be microbes misplaced. Microbes are present everywhere, and many of them do very useful work. Others are mischievous if they are misplaced, that is to say, if they gain admittance to some part of the body where they 


\section{2}

THE HEALTH OF THE CHILD

can multiply and where their poisonous products can be absorbed by the body. Above all, this is true of the microbes which are introduced with the food during the first year of life. These account for the fact that between two thousand and four thousand infants die of diarrhoea every year in London alone.

But the more one studies child-life, the more one becomes impressed by the importance of cleanliness-cleanliness of the body and of the clothes the infant wears, cleanliness of the room he lives in, cleanliness of the air he breathes, and above all, cleanliness of the food with which he is fed. 


\section{I}

\section{GROWTH AND DEVELOPMENT}

\section{Changes at Birth}

URING the nine months of the child's development in its mother's body before birth, it has been floating in a sterile and warm fluid with inert shrivelled lungs and empty stomach, all its needs being supplied by an interchange of materials between its own blood and that of the mother. At birth, a great revolution occurs. The lungs fill with air and are alternately expanded and relaxed some twenty times every minute. Food is introduced into the stomach and hence in future all the needs of the body for nourishment and fluid are supplied. There is for the first time a loss of heat and so the wonderful and complicated mechanism comes into play by which, whatever the external temperature, the temperature of the body remains constant within variations of a degree Fahrenheit. The senses receive stimuli, 


\section{THE HEALTH OF THE CHILD}

solid bodies are encountered, light assails the eyes, noises assault the ears. Lastly, the mouth and bowels, which up to now have been sterile, become the habitat of a large variety of microbes.

The readiness with which the baby takes to these changed surroundings is the first sign of a very encouraging characteristic of infant lifeits remarkable adaptability, within reasonable limits, to the most diverse conditions.

\section{Peculiarities of the Infant}

The Need for Support.-The infant cannot support itself on its limbs. It cannot hold its head up until it is 4 to 6 months old.

It is able to sit up when from 7 to 12 months old.

It is able to stand when from Io to I 5 months old.

(Note. These and other dates at which certain phenomena occur must be understood to be averages. The variations within the limits of health extend considerably beyond the average range.)

It is important to realise that no further support than rest for the body and head is 


\section{GROWTH AND DEVELOPMENT}

required. Mothers are often taught that the binder supports the body and prevents rupture. No such support for the body is called for. (See remarks on binders under the heading of clothing.)

Limitations in Dietary.-The infant has no teeth and its jaw muscles are adapted for sucking, not for chewing.

The digestive juices are such as are necessary for the digestion of milk-not for other diets. Thus, for example, the digestive juices in the adult convert starch into sugar; this the infant's juices are unable to achieve.

The entirely fluid diet and the small stomach entail small and frequent meals. The infant has less resistance than the adult to those microbes which cause diarrhoea.

The infant is very liable to vomit and it is well to consider the reasons for this.

I. The sudden flow of milk often necessitates unduly rapid swallowing.

2. The sense of satisfaction requires education, so that a vigorous child at the breast is apt to take more than it requires. This is why 'posseting' is thought to be a sign of good health. 


\section{THE HEALTH OF THE CHILD}

3. A considerable quantity of air is swallowed with the feed. By taking the child from the breast at intervals and putting it in a comfortable position, the air is belched up before the distress becomes so great that the whole feed is returned.

4. Infants have a great facility for vomiting. This is a safeguard when the child is healthy, a source of danger in ill-health.

Other Differences Between the ChILD AND THE ADULT

It is not altogether true that "the child is father to the man.'

Certain glands (for example, the thymus and lymph glands) are active in the child but not in the adult. With others (for example, the sexual glands) the reverse is true.

There are some diseases peculiar to childhood (e.g. Rickets); others are peculiar to adults (e.g. Gout). Children are far more susceptible to certain infectious diseases. (A person will often say 'I have had the ordinary childish complaints,' meaning chicken-pox, measles etc.). Lastly, a fact which seems very odd, 


\section{GROWTH AND DEVELOPMENT}

certain parasites (e.g. threadworms and ringworm of the scalp) only attack children.

\section{Mental Development}

A child develops a sense of touch and of temperature, and distinguishes between light and darkness immediately after birth.

At about 4 weeks, it follows objects with its eyes and is easily disturbed by noise.

At 3-5 months, it laughs aloud.

At 5-7 months, it is able to pick things up.

At Io-I 5 months, it is able to speak words.

At 2 years, it is able to make short sentences.

\section{WEIGHT}

The child's weight should be recorded once a week during the first year, and once a month during the second year. This record is of the greatest value as an indication of the welfare of the child. But it must be borne in mind :

I. That the rate of increase varies very widely, within limits of health.

2. That the weight may remain stationary or even decrease for a week without giving cause for alarm. For example, the nursing 


\section{THE HEALTH OF THE CHILD}

mother may be menstruating or the child may be teething.

3. That the weight may be steadily increasing though the child may be having a faulty diet. The child will, in this case, ultimately suffer.

\section{Average Weight}

Birth 7 lbs.

5 months $7 \times 2=\mathrm{I} 4 \mathrm{lbs}$.

I year $7 \times 3=2 \mathrm{I}$ lbs.

2 years $7 \times 4=28 \mathrm{lbs}$.

7 years $7 \times 7=49$ lbs.

\section{The Teeth}

Date of Eruption.-This is extremely variable. It is sufficient to remember that the lower central incisors should be the first to appear; that they should show between the $4^{\text {th }}$ and Ioth month, average 7 months; that at I2 months the child should have about 8 teeth; and that all 20 teeth should be present by the time the child is 2 years old.

The permanent teeth appear between the ages of 6 and I2 years with the exception of the wisdom teeth. 
Effects of Teething.-These are very much exaggerated by the laity. They are 'the refuge of the destitute'; that is to say, any unusual symptom, at the age of teething, is attributed to that cause. On the other hand, by a natural reaction, the effects of teething are apt to be under-estimated by doctors. Teething, more often than not, causes some salivation (dribbling), discomfort, as shown by the child constantly putting its fingers in its mouth, and loss of appetite. Further, there is reason to suppose that in some cases it produces an increased susceptibility to Bronchitis, Diarrhoea, nervous phenomena and skin eruptions.

\section{Decayed Teeth (Caries)}

There is a most unfortunately prevalent belief that it does not matter for the first teeth to be decayed. Nothing is further from the truth, and the subject is so important and so little undertood that it must be treated in some detail.

DANGERS

I. Channel for Infection.-The decayed teeth are a breeding ground for microbes and 
Tubercle bacilli have been found in them. These microbes are carried from the teeth into the glands in the neck and may thence be distributed to other parts of the body.

2. Indigestion, Anaemia and other constitutional disturbances may be and frequently are set up by swallowing the microbes and their products.

3. Inflammation of the Gums maintains a condition of chronic catarrh of the mouth and throat and is a fruitful source of enlarged tonsils and adenoids.

4. Difficulty in cherwing leads either to the bolting of unchewed lumps of food or to the child subsisting on a pappy diet ; in either case, indigestion results.

5. Pain which is often considerable may be a serious detriment; and distant nervous phenomena such as headaches and fits have been shown to have their origin in decayed teeth.

6. Undergrowth of the Jaws results from early decay of the milk teeth. Hence there is insufficient space for the permanent teeth and these, being crowded and irregular, decay rapidly in their turn. 


\section{Causes}

I. Faulty Diet is probably the chief cause. Too much starchy food or too little fat are the chief causes of Rickets, and this disease, even though present in very slight degree, is frequently associated with teeth which become very early the site of decay. Then again, it is rather the modern fashion, owing largely to the superabundance of prepared artificial foods on the market, to keep children on a soft and pappy diet which requires no mastication; the natural cleansing of the teeth and gums which comes from chewing hard food is therefore wanting; the soft starchy material collects between the teeth and in the sockets of the gums, and the products of its decomposition produce erosion of the enamel.

2. Heredity may be a factor. It is possible that there is a tendency in some families to produce teeth which are peculiarly subject to decay.

3. Lack of Attention.-The importance of scrupulous cleanliness follows from what has been said above as to the ill effects of food collecting about the teeth. 


\section{Prevention}

I. Dietetic.-The proper diet for children is described later. Here it is sufficient to say that as soon as the child has teeth it should be given some food which will require their employment. It is a good practice to give a hard cabin biscuit for supper. Fruit is very cleansing to the teeth and is therefore preferably given at the end of meals. Food should be strictly interdicted between meals, especially the promiscuous habit of eating sweets. There is no harm in such a sweet as good chocolate, but it should not be eaten at all times and in any quantity.

2. Cleaning the Teeth.-There are two important things to bear in mind. Firstly that brushing up and down is more important than brushing sideways though both should be done. Secondly, that however seldom they are cleaned, the cleaning last thing at night, after supper, should never be omitted.

3. The Dentist.-Dentists are perhaps not altogether free from blame with regard to the general attitude of mothers on this subject. But, undoubtedly the best dentists recognise 


\section{GROWTH AND DEVELOPMENT I3}

its importance. It must be remembered that the slight filling that these temporary teeth require does not entail the agony that adults are wont to associate with the dentist's chair. Further, when the teeth cannot be filled, the decay can often be arrested by the painless use of caustics. The great difficulty for the working class mother is the expense. The establishment of dental clinics throughout the country cannot, it is to be hoped, be much longer delayed. 


\section{THE HEALTH OF THE CHILD BEFORE BIRTH}

DURING the nine months of pregnancy, the mother is making a new human being. This is a considerable undertaking. The mother must, therefore, be especially careful about her own health and must have more rest than usual. In the case of a busy woman, a good many of her usual activities must be curtailed. Nevertheless, pregnancy is a perfectly natural condition and there is no need for the mother to be treated as an invalid. Little more than ordinary common sense is required as a guide to the expectant mother.

Indigestion.-Bad teeth in the mother prove a fruitful source of trouble during pregnancy and should have immediate attention.

A certain amount of trouble with digestion is the rule, and the appetite may be very capricious. Usually there is one time in the 
day when the mother feels really hungry and advantage must be taken of this to make a proper meal. The craving for unusual foods may be satisfied within reasonable limits, but it is a mistake, for instance, to indulge in pickles or large quantities of vinegar.

For the heart-burn so common at night, a little Bi-carbonate of Soda in water or in the form of soda-mint tablets is a great boon.

Constipation is common. Plenty of fruit, cooked and raw, green vegetables and two or three tumblers of water during the day (hot or cold, it matters not which) will alleviate it. A dessert-spoonful of refined Paraffin after meals will help. Other aperients such as Infusion of Senna-Pods or some form of Cascara Sagrada may be required, but a strong purge should never be taken. When the condition has become severe, a simple enema is safer.

Exercise and Rest.-It is very important that a proper amount of exercise be taken daily in the fresh air, but the mother must be very careful to subject herself to no sudden strain. She should not, for instance, push the garden roller, open a window that has stuck, or lift a heavy child, or a heavy piece of furniture. 
She should lie down every afternoon, at any rate during the latter months of pregnancy and, if she feels lazy, she must remember that she is doing good work which will show in due course. To the working-woman this is a counsel of perfection; in the factories there is here the opportunity for her more happilyplaced sisters to work for some much needed reforms. Whenever the mother is resting, she should have her legs up to relieve the pressure on the veins.

The Mind.-It is more important than ever to keep one's mind in wholesome occupation and, by the exercise of proper self-control, to remain calm and cheerful. So-called 'Maternal Impressions '-that is, a physical defect or blemish in a child resulting from a shock or fright to the mother-have, in my opinion, no foundation in fact and the belief has given rise to a great deal of unnecessary apprehension. But if the mother worries and frets unduly the value of the nourishment that the growing child is receiving will diminish. This is obvious after birth when the mother is feeding the child and, though less evident, is no less true before birth. 


\section{III}

\section{FOOD AND FEEDING}

I F all the babies of England of to-day were 1 breast fed and only breast fed for the first eight months, the effect in the course of one generation would be very obvious. There would be a tremendous increase in the number of children who survive the first year; there would be an almost complete disappearance of Rickets and all its associated conditionsthere would probably be a great decrease in Tuberculous diseases of children. Above all there would be a magnificent increase in the number of thoroughly healthy boys and girls, and ultimately men and women, who had not had their inherent natural vitality sapped during the first year of life.

It is not inconceivable, though at present it appears highly improbable, that some day man will be able to improve upon Nature, and produce a better food for infants than their 


\section{I8 THE HEALTH OF THE CHILD}

mother's milk. But at present there is nothing to compare with it.

\section{Advantages of Human MilK}

There are probably qualities in human milk which we do not at present understand which account in part for the difficulty in replacing it satisfactorily. We do know that artificial foods and boiled milk lack something that is essential in the diet of a child, but what it is has not yet come to light. The only alternative in general use to human milk in the first months of life is cow's milk (goat's milk might be more widely used with advantage) and cow's milk is lacking in two very important qualities.

I. Digestibility.-Milk contains two proteids, one (Casein) which forms a curd in the stomach, and another (Lact-albumin) which remains in solution. Now the Casein is not only present in much larger proportion in cow's milk than in human milk, but further, it forms a much firmer clot or curd than does human casein. For this reason cow's milk requires to be largely diluted to prevent curd-indigestion, and then one is faced with a deficiency of fat, sugar and lact-albumin 


\section{FOOD AND FEEDING}

which have to be made up in one way or another.

2. Cleanliness.-Human milk, for all practical purposes, may be considered sterile. Cow's milk on the other hand collected under the best conditions is far from sterile, and under the conditions of town life is often teaming with a large variety of microbes. Ten per cent. of London milk contains Tubercle bacilli. With regard to the danger from other microbes, it is sufficient comment to state that of the children dying from diarrhoea at Great Ormond Street Hospital, it was found that 96 per cent. were hand-fed.

\section{Causes for Hand-Feeding}

The chief cause is unknown. That is to say, a vast number of mothers have not got sufficient milk with which to feed their babies and the cause of this is not known. Possibly in animals, this condition is kept at a minimum by a process of natural selection, for it is obvious that a female who could not nourish her offspring would fail to leave survivors.

The mother working away from home is a 


\section{THE HEALTH OF THE CHILD}

fruitful cause in industrial centres for recourse to hand-feeding.

Fashionable mothers often prefer to sacrifice the welfare of the child to the pleasures of selfindulgence. Amongst the better-educated classes this is not however so widespread a trouble as is the fact that many mothers are too easily discouraged. Sometimes unfortunately, this discouragement comes from the monthly nurse. The motions of a breast-fed baby are often rather inclined to be loose and green. Their appearance is quite often not so satisfactory as in the case of a hand-fed baby. It is this which often leads to the mistaken advice of the nurse. But it need cause no alarm if the baby is not losing weight. Sometimes the mother's nervous system, ill-tuned to the strain of modern life, is inadequate to supply this function. Sometimes the mother tries to compromise, to satisfy the needs of her baby and of society and fails to take sufficient rest. Insufficient food for the mother has not so great an effect on the milk as is often supposed, but overfeeding sometimes defeats its own end by upsetting the health of the mother. Tender or ill-developed nipples 
are often a trouble at first, and are not treated with sufficient patience. Where the mother begins to feed the baby and then desists, one of two reasons is usually given.

I. 'The milk is not satisfying the baby.' In this connection, there are three things to be remembered. First, the cry of indigestion is often mistaken for the cry of hunger. The only safe criterion is the weight record. Secondly, one can sometimes manage quite well for some weeks by letting the baby have both breasts at each feed. Thirdly, where the milk is really inadequate there is no objection to combined breast and hand feeding. Often, a slight relief to the mother is all that is required -for instance, one bottle in the afternoon. In other cases, the mother is able to give the breast at night and the bottle during the day.

2. 'The milk does not agree with the baby.' This complaint often follows from the mistake just mentioned. The baby cries because it has some pain from flatulence or constipation, and the mother thinking that it is hungry feeds it again, thus aggravating the discomfort which she is trying to relieve. Regularity in feeding is of the greatest importance. 


\section{THE HEALTH OF THE CHILD}

An infant very readily acquires habits. It should be wakened up during the day for its feeds, and then soon acquires the habit of waking at the right times. It must be remembered that the younger the infant the more important is breast-feeding, so that there is a great gain, even if the mother can only feed the child during the first two months, in her doing so. There is a common fallacy that the onset of menstruation is an objection to the continuance of breast-feeding. This is not so.

\section{Details of Breast-Feeding}

During the last month of pregnancy, it is a good plan to sponge the nipples with brandy or eau-de-cologne. The nipple should be washed before each feed, and after the feed the milk should be washed off and glycerine and borax mixed with an equal quantity of brandy applied. Great care should be taken to hold the breast back so that the child's nostrils are free while it is sucking. If the flow is too fast the child should be occasionally withdrawn. If the nipples are tender, shields should be used. The mother must take sufficient rest ; often as soon as she sets about her household 


\section{FOOD AND FEEDING}

duties or satisfies her social calls, the supply of milk diminishes. At the same time she should take some exercise. A very special diet is often unnecessarily ordered. All that is required is that, without being so excessive as to cause indigestion, it should be more plentiful than usual, and the most wholesome way to increase it is to add simple milk foods such as gruel. It must be remembered that many medicines are excreted with the milk. With regard to alcohol it sometimes seems to have a deleterious effect upon the milk, though many mothers take a little stout without any apparent bad results.

\section{FREQUeNCY OF FeEdS}

No hard and fast rule can be applied. The important things are that whatever intervals are determined on should be rigidly adhered to, and that the changes which are necessary as the child grows older should be introduced gradually. Roughly the feeds should be, during the day, every 2 to $2 \frac{1}{2}$ hours for the first 3 months, and subsequently every 3 hours. At night the child should be fed every 3 hours for the first 3 months; from the $4^{\text {th }}$ month it 


\section{THE HEALTH OF THE CHILD}

should be able to go 6 hours at night without a feed, getting on to 9 hours about the 6th or 7 th month.

As has been said, it should be wakened during the day regularly for its feeds, but this is not necessary at night.

\section{HAND-FEeding}

The Bottle.-There is one thing which chiefly distinguishes the good from the bad bottlenamely, the ease with which it can be cleaned. The 'Little Folks' and 'Allenbury' are two good types and the former is very cheap. These are bottles which have an opening at each end. Unfortunately bottles with tubes attached are still used though the danger of such dirt-traps must be evident to all. The opening in the teat should be such that the milk will drop through very slowly when the bottle is held teat downwards.

It has been pointed out that the dangers of cow's milk are its indigestibility and its extraneous contents. The latter include-

I. Disease Germs from unhealthy cows.

2. Dirt from the cow, the milker, the receptacle, or the vehicle of transit. The greatest incredulity must be exercised with 
regard to the statements of the purveyor. It is not uncommon for bottled milk which is guaranteed to be sealed immediately on milking, to be put into the bottle at the back door of the purchaser, and the cap to be taken out of the milk-man's pocket and there and then attached to the bottle.

3. Preservatives may be added to the milk although there is not much evidence of any wide-spread danger from this source.

Nursery Milk is to be avoided. It is from a few cows instead of from many, and is therefore more likely to show a wide departure from the average composition. Sometimes when it is from Jersey cows exclusively, it is too rich in cream.

Varieties of Doctrine.-The mother who attempts to get a clear view of all that is taught about the modification of cow's milk will find herself lost in a wilderness of contradiction, unsupported hypotheses and directions so elaborate as to be quite impracticable. She will seem to be hedged in between alternative diseases whose very names make her shudder. If not Tubercle and Diarrhoea from new milk, then Scurvy from cooked milk ; if not Indigestion and Marasmus from cow's milk, then 


\section{THE HEALTH OF THE CHILD}

Rickets from artificial food. She will have to study percentage compositions which assume a knowledge of higher mathematics. She will have to study the large variety of creams on the market, and to become familiar with the characteristics of Demerara sugar, milk sugar, beet sugar and grape sugar. Much other chemical lore must she attain before she can consider herself at home with the subject.

Here it is proposed to give first general directions of the simplest sort and then to discuss certain details.

General Directions for a Working Class WOMAN

Order ordinary milk from the cleanest dairy you know.

Stand the milk in a basin or jug, covered with a piece of clean paper, for one hour.

Ladle off the top part for use. Add tap-water as follows:

Ist month I part milk, 3 parts water 2nd and 3rd months I $4^{\text {th }}$ and $5^{\text {th }}$ 6 th and 7 th

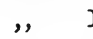

"2 2 parts ,"
2 ,

I part ,

I,
,

,

8th month Plain milk 
Add one ordinary lump of sugar to each feed, a rather small lump at first, a big lump later on.

Heat the milk until bubbles just begin to rise but not so that it rises to the boil.

Give milk to baby lukewarm. Do not test this by sucking but by letting drops fall on to front of the wrist.

Quantity of each meal :

$\begin{array}{ll}\text { Ist month } & \text { I } \frac{1}{2}-2 \mathrm{oz} . \\ \text { 2nd } ", & 2-3 \mathrm{oz} . \\ \text { 3rd " } & 3 \mathrm{oz} .\end{array}$

Up to end of 8 months, add I oz. for each month.

After feeding, turn teat inside out, thoroughly wash bottle and teat and keep in clean water.

Scald bottles once a day.

With these general directions as a basis we can now consider the matter in a little more detail.

I. Make all changes gradually.-The only exception to this is when you have to weaken the milk because of vomiting or diarrhoea.

2. Too much or too strong food is a much more common fault than food too weak or too little. 
28 THE HEALTH OF THE CHILD

3. Determine changes by (a) Weight record. (b) The motions. (c) Signs of abdominal discomfort. (d) General condition-colour, firmness, liveliness.

In this connection it must be noted that the deceptive results of patent food feeding is one of its worst features ; for $a, b$ and $c$ may all be satisfactory for some time on such a diet, whilst Rickets is gradually developing. But on cow's milk modified as above, the weight record is a very reliable test of the general condition and progress of the child.

4. Curd Indigestion.-Individual babies differ very widely in their ability to deal with the heavy tough curd that cow's milk forms in the stomach. Some babies appear to be able to digest plain undiluted cow's milk from birth, whilst others have trouble even when the dilution is such that the proportion of casein present is less than the proportion in human milk. A very simple, safe and effectual remedy for these latter is to add sodium citrate, one grain to each ounce of milk. The only objection to this modification is that it is often slightly constipating.

5. The colour and consistency of the motions is 


\section{FOOD AND FEEDING}

more important than whether the baby has one or four actions in the twenty-four hours. There should be no hard lumps, no undigested curd, no mucus (slime), no green colour.

6. If a child is not getting enough food, increase the strength of the food rather than the bulk.

7. Sugar.-Milk sugar is better than ordinary sugar, partly on the general principle that one should follow Nature as nearly as possible, and partly because it has a slight laxative value.

8. Cream.-China dishes can be obtained with two spouts, one of which runs to the bottom of the dish. These are very convenient for separating off the upper portion of the milk. If 'shop-cream' is bought, it must be remembered that its strength varies very considerably and that owing to its concentration, it is very easy to add too much. It should of course be added before scalding.

9. The Diluent. Barley water is very commonly recommended. It is possible that, to a slight extent, it prevents curd indigestion, but it contains a small quantity of starch which may itself cause indigestion. Lime water is also popular. Cow's milk contains a great 


\section{THE HEALTH OF THE CHILD}

deal more lime than does human milk. Nothing is better than ordinary water from a good supply.

\section{Faults of Hand-Feeding}

Dirty milk.-We are all agreed that the milk during the first eight months should not be boiled, but dangerous microbes can be killed by a temperature, short of boiling-point, which does not destroy the unknown but valuable constituents which are lost in boiled milk. If this is done more or less accurately (as by an Aymard or Soxhlet apparatus) it is called Pasteurizing. Both the Aymard and the Soxhlet can be obtained readily and are easily worked. One of these or some similar contrivance should be used by all mothers who can afford them. Those who cannot should scald the milk as described. When you consider that town milk is often 24 hours old before it is delivered, that often it is produced roo miles away from the town, that Io per cent. of London milk contains Tubercle bacilli, and above all, the figures of mortality from diarrhoea in infants, the reasons for this precaution become evident. Moreover, the 


\section{FOOD AND FEEDING}

figures of mortality give no idea of the debility produced in those who recover, and who often subsequently succumb to some other illness owing to their weak state.

In spite of these cogent reasons for scalding milk, certain arguments have been adduced against the practice and these deserve consideration.

I. The possibility of destroying valuable qualities.-It is suggested that as boiling the milk has bad results which are evident, heating it to a less degree may have similar though less evident results. This hypothesis is not supported by experience.

2. Destroying the microbes prevents acquired immunity.-The theory is that the baby by swallowing dangerous microbes insufficient in number to produce disease acquires a resistance to them which is of value. The answer is two-fold. First that the immunity is acquired at too great a cost. Secondly, it is not acquired until the period when it was most needed has passed, that is to say, the period when the diet is milk only.

3. The alleged harmlessness of Tubercle bacilli from the cow.-All we can say here is that the 


\section{THE HEALTH OF THE CHILD}

weight of the evidence preponderates against this view.

On paper, it appears safe to give unheated milk where you have a model dairy, an efficient refrigerator apparatus, scrupulous cleanliness and strict Tuberculin testing of the cattle. But in practice the difficulty is that the more nearly perfect such a scheme is at the onset, the demand for the milk is such that the details of organisation have to be left in the hands of a large number of people, and this inevitably leaves room for mismanagement and carelessness.

4. The milk is less appetising.-In older children, during the second and third year, this is sometimes a slight drawback, but by then milk is only a subsidiary, though still a very important article of diet.

My own view therefore is that the weight of the evidence is overwhelmingly in favour of Pasteurizing the milk during the first year at least.

Too large a quantity to each feed.-This is a possibility which, though perhaps not so common as some authorities hold, is apt to be forgotten. The great ease with which good or 


\section{FOOD AND FEEDING}

bad habits are induced in infants must always be borne in mind. By making the intervals between meals too long or by making the meals themselves too weak, a larger bulk of food than the stomach is fit for is introduced. The stomach becomes dilated, and although the child shows no ill effect for a time, vomiting and wasting may subsequently ensue.

Too much carbohydrate.-Many patent foods, advertised as containing no starch, contain large quantities of what is called ' converted starch,' that is to say, starch which has gone through the first step of its change into sugar. Now if you have too much starch or converted starch or sugar in the feeds, there are direct and indirect bad effects. The former are flatulence with associated vomiting and looseness of the bowels. The indirect effects are apparently that the absorption of fat is interfered with and are therefore the same as those produced by too little fat in the food-namely Rickets. This is one of the chief reasons for insisting that patent foods should never be used as the staple article of diet but only as a temporary expedient.

Too little fat.- ' The chief dietetic factor in 


\section{THE HEALTH OF THE CHILD}

the production of Rickets is deficiency of fat assimilation' (Still). Various substitutes for cream-such as suet-have been recommended but the great advantage of the natural milk-fat is that it is more finely divided and more intimately united with the other food constituents than any extraneous fat artificially mixed with the milk can be.

Too much fat.-Babies have a remarkable capacity for digesting and absorbing fat. Nevertheless, if the concentrated creams supplied by dairies are added to the milk, it is very easy to produce too high a proportion of fat with consequent indigestion and wasting.

Figures are of little use to those who are not trained to deal with them. But it may be well to remind the reader that cow's milk contains the same proportion of fat as does human milk, double the quantity of proteid and about half the quantity of sugar.

\section{Patent Foods}

Their name is legion, but they fall into two groups-substitutes for cow's milk and additions to cow's milk. Many of them have proved highly valuable as temporary expedients for 
tiding a baby over a dangerous period when its ordinary diet is unsuitable. But it would be difficult to exaggerate the amount of harm that is done by their indiscriminate use. The baby is not getting on. The mother and doctor between them have tried in rather a haphazard way several modifications of cow's milk with no very satisfactory results. A friend's baby has been saved by somebody's food. The food is tried. The results fulfil every prediction. The motions immediately improve, the mother enjoys the first restful nights she has had for weeks, the baby laughs and the weight increases. It is little wonder that so satisfactory a diet is made a permanency. And it is difficult to convince the uninitiated mother, six months or a year later, that the trouble from which the child is sufferinganaemia, flabby muscles, a pigeon chest or a pot-belly, croup or convulsions, teeth that decay as soon as they appear, bowed-legs, backwardness in mental development or whatever it may be-is due to the continued use of the food. These are amongst the many manifestations of Rickets. There is a prevalent belief that Rickets is a very obvious and terrible 


\section{THE HEALTH OF THE CHILD}

disease due to gross mismanagement. This is an error. The slighter signs of Rickets are extremely common amongst the babies of the educated classes and can only be recognized as such by those who are familiar with the disease. Nor should we say that it is necessarily very dreadful for a child to have a very mild form of the disease. With appropriate treatment the trouble can usually be adequately dealt with. Yet, even in its mildest form it is usually a great hindrance to the proper development of the child. The child will never be quite so fine a specimen of humanity as it would have been had it been properly fed. And that verdict when applied as it must be to many thousands of the nation's children is a very serious indictment indeed. Rickets is a preventable disease, and the benefit to the nation that would accrue from its entire suppression would be enormous.

The other disease that arises from the abuse of patent foods is Infantile Scurvy. Many people think that this result is surely prevented so long as the child is having some unboiled milk. This is not so. 'A large proportion of cases of Infantile Scurvy arise when a 


\section{FOOD AND FEEDING}

patent food is being added to fresh milk' (Still). Now this disease is not obvious to those who are not familiar with it and it is not common. But the possibility must always be borne in mind, when we depart far from Nature, that bad results of a minor degree may be produced, not sufficiently manifest for doctors to have noted them, checked them, classified them and named them, but yet to be avoided if possible. That is why the practice of giving some fresh food, even when the milk is only being Pasteurized and no patent food is used, is much in favour. Probably it would be well for every baby who is being fed on Pasteurized milk to be given some orangejuice or grape-juice from the fifth month, beginning with a teaspoonful once a day.

\section{The Diet from 9 Months to 2 Years}

We cannot do better than quote the admirable words of Dr. Still.

' From nine months old up to the end of the tenth month, an infant should not have more than one meal a day of starch-containing food : I like Robb's Biscuits or “Malted Rusks" for a start, but at this time there is no objection 


\section{THE HEALTH OF THE CHILD}

to any of the partially malted cereal foods or to the unconverted cereal foods, only let it be quite clear that such "foods" are to be given only once a day.

'At the age of eleven months two starch containing meals can be given in the day, one of which I think may advantageously be a milkpudding either of pearl sago or ground rice. The rest of the feeds are to be milk, not less than $\mathrm{I}_{2} \frac{1}{2}$ pints of milk should be taken daily. In addition the yolk of an egg very lightly boiled should be given daily from the age of nine months.

'After the age of twelve months a dessertspoonful of gravy of fried bacon with a little crumbled bread soaked in it makes a valuable food. Throughout the second year it is most important that a child should have abundance of milk and that the diet should not be too largely starch-containing. Chicken or veal broth, fish, boiled brains, red gravy, custard, blancmange, all these are useful as variations.'

During the second year, a small portion of potato may be given daily with the fish or gravy. Fruit jelly, marmalade, treacle and honey may be used in moderation. Any green 
stuffs which will pass through a sieve, or better still, which have passed through a sieve, such as spinach and the flower of cauliflower are of great benefit. So are baked apples, prune juice and fig juice.

\section{Diet of a Child From 2 TO 4 Years}

If a child wakes about 6 and has breakfast at 8 , it may be given a biscuit or a crust of bread or some fruit on waking.

Breakfast consists of porridge with milk and sugar followed by a boiled egg, fish or baconfat with fried bread; also bread and butter with marmalade, syrup or jam; milk to drink.

Lunch at II. A biscuit, fruit (apple, banana, orange) and water to drink.

Dinner at I or half-past. Meat or broth or fish or poultry. Green vegetables and potatoes -especially those boiled in their skins or mashed. Milk-puddings and stewed fruit, bread-and-butter pudding or suet pudding (apple dumplings, roly-poly or treacle pudding). Water to drink.

Tea at 4.30 or 5. Bread with butter, dripping or jam, milk to drink. Simple cakes and 


\section{THE HEALTH OF THE CHILD}

occasionally for the older children, an egg or sardine.

Supper at bed-time, 6.30 or 7 . Groats or bread and butter or rusks and milk or water as the child prefers. (See also p. 43.)

\section{The Diet of Older Children}

It is very difficult to weigh up the pros and cons of 'indigestible' food, by which is meant not unwholesome food such as pastry, hot buttered toast, pickles and spices, but food which leaves a large residue which cannot be dissolved by the digestive juices and passes out unchanged in the motion. Such are wholemeal bread, coarse porridge, raw fruits such as bananas, apples and oranges, raw vegetables such as radishes and lettuce and some cooked vegetables, especially cabbage. The stomach and bowel constitute from one point of view a long hollow muscle, and this muscle like all others requires exercise to keep it in condition. It has been shown that rabbits fed on food from which all the indigestible material has been removed rapidly succumb. It is highly probable that many of the complaints of adults arise from too pappy a diet during childhood. 
The bowel muscles, insufficiently stimulated, have become sluggish and enfeebled. Moreover it is of the greatest importance for the proper development of the jaws and teeth that the food should require plenty of chewing. Finally, chewing fruit pulp has a very beneficial effect in cleansing the teeth and gums.

Against these arguments are first the fact that with the utmost patience and ingenuity, it is difficult to prevent some children from bolting their food and secondly the actual experience of doctors that large numbers of children who suffer from colicky pains or who pass motions containing mucus (slime) or who seem unaccountably tired and puffy under the eyes improve rapidly when put on a diet in which indigestible foods are avoided. Colic is a common trouble of childhood, and though it is often due to constipation, it is sometimes due to the food which has been given in the hope of curing this complaint.

To sum up, indigestible foods in reasonraw apples, porridge, bananas, oranges and so forth-are wholesome and serviceable. But if the child cannot be made to chew properly 


\section{THE HEALTH OF THE CHILD}

or if it show signs of indigestion, they should be avoided.

Idiosyncrasy.-With certain articles of diet, one child's meat is another child's poison. This is true, for instance, of eggs, which though very suitable food for the great majority of children, invariably upset others even in the form of custard.

Fad and instinct.-This is one of the most difficult distinctions to draw correctly. For instance, a child complains every time meat is put before it, and when pressed to eat it, the meat is packed in the mouth without being swallowed, or, under extreme pressure, is swallowed in tears and presently returned. It is difficult to believe that while the child is crying out against the meat, its system is crying for the want of it. This difficulty is most marked when the child is 'spoiled.' A spoiled child, like any other damaged mechanism, never works smoothly; and as a bad workman blames his tools which he has mishandled, so you will hear the despairing mother of the spoiled child declare 'nothing pleases him.' But if a child has been trained not to make fusses, to obey promptly and to take the day's events 
cheerily-if such a child shows a strong repugnance to certain kinds of food, then it is probable that he is as well or better without it. Green vegetables seem to constitute a class in themselves in that the relish for them appears to be an acquired taste, and yet they are universally allowed to be a wholesome article of diet. The best plan in this case is to insist on a minute portion everyday-just a mouthful and presently it is found, if this course be persisted in, that the child asks for more.

Fat is very good for children in the form of butter, beef-dripping, and bacon fat. It is partly on account of the oil, that sardines are a useful article of diet for children.

Starch can be given in excess. Potatoes, bread and butter and biscuits are all good, but must all be used in moderation.

Feeding between meals should be strictly forbidden.

Heavy suppers are bad.-A substantial tea should be followed by a hard biscuit and water for supper.

Spiced foods, pickles, curries, tea and coffee are bad. The best drink is milk with a little hot water and sugar; cocoa once a day in 


\section{THE HEALTH OF THE CHILD}

winter; tea and coffee will creep in sooner or later, but the later the better.

Cold meat and twice cooked meat cannot be altogether avoided in most households, but they should not be given more than about twice a week.

Bolting the food can be largely prevented by encouraging conversation at meals. Nothing is more characteristic of the perverted taste of the early Victorians than the saying that the child should be seen and not heard.

A child well or ill, whatever the illness, may always have as much water as he wishes. -It is true that it is undesirable to drink a large bulk of cold water very rapidly. But from this small and unimportant fact has arisen an extraordinary prejudice against the drinking of cold water. The amount of suffering that is endured by children who for one reason or another are feverish, and therefore thirsty, but from whom water is carefully withheld, is terrible. A child loses water by the skin, the lungs and the kidneys more rapidly than does an adult. The child should be encouraged at all times to drink as much water as it will. Here it may be mentioned that a common 
trouble with children is for the urine to be too concentrated and therefore irritating, causing the child to feel a frequent desire to void it. Usually water is then carefully withheld when a free and abundant supply of it is all that is required to relieve the complaint.

\section{Constipation in Infants}

This curse of civilized races is not so common in breast-fed infants as in those who are handfed. Yet even in the former it is sadly prevalent. The causes are still obscure. At all ages it is of the utmost importance to practise a regularity of habit. The youngest infant should be 'held out' unfailingly at certain definite times. That constipation is amongst the possible bad effects of not letting the child kick freely without its napkin is dealt with elsewhere (clothing).

Symptoms.-Constipation is the chief cause of flatulence and colic in infants. The colic is either due to the flatulence or directly caused by the presence of hard lumps in the bowel. In severe cases it leads to vomiting and wasting, and then often the mother confuses the cause and result, and tells you that the child is pass- 


\section{THE HEALTH OF THE CHILD}

ing so little because it takes so little. It is a common mistake to believe that the motion is merely the unabsorbed remains of the food. A large part of it is in fact an excretion from the lining of the bowel and this excretion goes on whether food is being taken or not.

Cure.-The first thing is to see that the proper food is being given, especially that there is no deficiency of cream. Manna, which has an old established reputation, is very disappointing. Olive oil in small half teaspoonfuls twice a day, is very good. This is partially absorbed as a food. The pure liquid paraffin of the chemists is not absorbed, and is therefore in some ways more efficacious. Magnesia is an innocent and reliable remedy. Dinneford's Magnesia is a great stand-by during the first year. If these methods fail, medical advice must be sought.

The orange juice which has been recommended as a routine article of diet after six months is slightly laxative, and as an alternative prune juice may be tried.

Castor oil is very constipating.-A large dose is the safest purge we know and is invaluable where it is desired to ged rid of any poison in 


\section{FOOD AND FEEDING}

the bowels; that is why it is so useful at the onset of diarrhoea. But one should never try to use it as a regular aperient ; the child becomes more and more constipated. Its chief use in babies is its efficacy in restoring the motions to the normal when they are loose and green and offensive, when administered in the form of a few drops several times a day. (Three drops with each feed in a baby of three months.)

Mercury in the form of Grey Powder or Calomel is a very useful occasional aperient, especially when the child is a little 'out of sorts,' but it is best given under doctor's directions.

Enemas.-Six ounces of soapy water, a teaspoonful of plain glycerine or a piece of yellow soap shaped like the top of one's little finger are very useful in an emergency, but as a routine practice they are bad, as the child comes to depend on this unnatural stimulus.

Older Children.-Lack of exercise, heavy clothing, bad teeth with consequent pappy diet, insufficient water to drink, careless habitsthese are the common errors. Often the child, not understanding the importance of the 


\section{THE HEALTH OF THE CHILD}

matter, cannot be persuaded to make the requisite effort. In these cases, a little moral suasion-a reward for success or a deprivation for failure-will often work wonders.

Paraffin is a harmless adjuvant and is well taken when mixed with liquid extract of malt. It differs from other aperients in that it has no chemical action but is merely a lubricant; it passes through the body unchanged. Aperients should not be given casually. If unhappily they are required the proper method is to give the smallest effectual dose regularly over a prolonged period.

Some form of Senna-Senna pods, Syrup of Senna or Liquorice Powder (in which the active ingredients are senna and sulphur)-is the best stand-by.

\section{DiARRHOEA}

It is to be hoped that the appalling mortality of infants from this complaint and its prevention by scrupulous cleanliness are beginning to be realised by the public. Unhappily the knowledge has not yet brought with it any general improvement. It is important to grasp the fact that the danger in acute 


\section{FOOD AND FEEDING}

diarrhoea and vomiting is not want of nourishment but lack of fluid. A child can live for a long time on its own tissues, but a minimum amount of water in the blood and tissues is essential to life. Many a life is lost through the mother persisting with milk, where its replacement by plain water would have meant the child's recovery. It is a good general rule, whenever an infant ails, to dilute its feed at once. With acute diarrhoea, it is better to put the child on to albumen water at once (see p. 89), and obtain medical advice. The epidemic diarrhoea and vomiting appears in the hot months and is worst in September. The cure lies in the hands of the doctors; but prevention lies in the hands of the mothers. It is at these times especially that one cannot be too watchful over the cleanliness of the milk and of the bottle and of anything which may be within the baby's reach, and is therefore likely to be put in his mouth. The milk should never be left uncovered; it is probable that the house fly plays a large part in spreading diseases of this sort. The mother may have an unhealthy mouth and should therefore never suck the teat in order to see whether it 


\section{THE HEALTH OF THE CHILD}

is drawing or to taste the feed. The feed may be tested by pouring a little into a teaspoon. If the hole in the teat is too small it may be enlarged by a needle, heated in a flame. 


\section{IV}

HYGIENE OF THE NURSERY

WASHING

THE 'pores of the skin' are the openings

1 of innumerable glands which discharge on to the surface of the skin a fluid called sweat or perspiration. This excretion continues all the time but, for the most part, evaporates as it exudes. It is only when it is poured out very fast as when one is very hot that it makes the skin sensibly moist. The presence of these little glands and their excretion is one reason for being very careful to keep the skin clean.

A baby's skin is very apt to get sore for three reasons-because it is tender, because there are many creases and because it is frequently soiled. A large amount of suffering is entailed upon babies, and a great many babies are dubbed fretful or bad tempered through lack of detailed attention to the care of the skin.

I cannot agree with those who sanction the 


\section{THE HEALTH OF THE CHILD}

use of a napkin which has been wet with urine and dried again. Soiled napkins should be put to soak immediately on removal, and subsequently washed with soap and hot water. The soap should be thoroughly removed. They should be boiled twice a week.

Soda should never be put into the water in which napkins are washed.

The water in which a baby is bathed should be comfortably warm; if your hands are not very sensitive the elbow should be used to test it. It is not desirable to insist upon the use of a thermometer. Scientific accuracy is excellent; but a 'counsel of perfection' often means to overburden and harass the conscientious mother whilst the one with less scruples turns a deaf ear to all advice and trusts to the teachings of tradition.

It is quite enough to sponge the baby with water in the morning and use soap at night; the points of importance are that the soap should be a sound 'superfatted' soap and that it should be well washed off. The greatest care should be taken to clean in the folds and creases, especially in the groins and behind the ears, and to see that these parts are thoroughly 


\section{HYGIENE OF THE NURSERY}

dry and that they are then well powdered. Equal parts of starch and boracic acid make an excellent powder.

There is a tendency nowadays to do too much cleaning of the nose and mouth. Poking things up the nose may easily damage the delicate structures therein. A healthy baby who is not allowed to suck dirty things does not get 'thrush' whether his mouth is cleaned or not.

If any soreness of the buttocks appears, as may happen with the most careful nurses, the application of a little boracic vaseline or Fuller's earth cream will often check it.

An interval of an hour should elapse between an infant's bath and its last feed.

Cold sponging should be begun when a child is three or four, letting him or her stand in warm water at first; if he is a vigorous child, the warm water can soon be stopped.

Cold baths have an excellent bracing effect. A mother often wonders if her child is strong enough for cold baths. The answer is that if the child is warm and comfortable as soon as he has had a rub down, all is well; but if he is blue and shivering for some time after his 


\section{THE HEALTH OF THE CHILD}

bath, it should be replaced by a tepid sponge.

Scurf is best treated by the use of rain water, a superfatted soap and as little as possible of it and the application of the chemist's pure liquid paraffin.

\section{Ciothing}

Clothes are for warmth, not for support.

The essentials are that the clothes should be light, they should completely cover the body and limbs, they should be absorbent, they should be free from all constrictions, they should be easily put on and removed, and they should be of as little bulk as possible to permit of the free movements of the limbs.

As soon as the cord is off, the binder should be discarded and a deep knitted woollen belt replace it.

It is difficult to speak with moderation of the enormous amount of suffering that ensues from the use of the traditional binder. Over and over again one sees an unhappy infant so constricted in its many folds that one cannot get one's fingers between the flannel and the skin. One is told that it is 'for support,' or 


\section{HYGIENE OF THE NURSERY}

by the more learned ' to prevent rupture.' A baby does not require support and a properly constructed baby needs no application to prevent rupture. If there is a protrusion at the navel, after the cord has come off, a boiled penny in a piece of clean flannel secured by some small strips of ' zinc strapping' and kept in place for a few weeks is all that is required.

It is much more common to burden the baby with too many clothes than the reverse fault of letting it wear too few.

The napkin should have as little bulk as possible. A healthy naked infant, when awake, kicks up and down all the time with great vigour. This kneads and shakes up the abdomen and is an effectual aid to the healthy action of the bowels. With a thick wad of napkin between the thighs and abdomen, this important gymnastic is quite impossible. It is therefore very desirable to let the baby lie totally naked in a sufficiently warm place for some ten minutes or so, two or three times a day. It is probable that the lack of this ' auto-massage' accounts in part for the prevalence of constipation in civilized infants.

In older children (up to three years of age, 
56 THE HEALTH OF THE CHILD

or if the child be at all delicate, throughout childhood) the half-bare leg is to be deprecated. It is true that long stockings require much darning about the knees and entail the use of some sort of suspender. But these disadvantages do not outweigh the benefit of a proper covering. In hot weather, shoes and stockings may be discarded altogether. This is a great joy to the child and allows the free use of the foot-muscles. To poor mothers it saves considerable expense. The foot gear is of the greatest importance. Ill-fitting shoes not only produce ugly and uncomfortable feet with corns and bunions and hammer-toes in the years to come, but the discomfort of the child checks its natural impulse to race about and thus adequately exercise its body. Properly fitting shoes well repay any extra cost and trouble there may be in getting them.

\section{The Nursery}

The best day nursery is the garden in fine weather, the verandah or open shelter in wet. In connection with schools and crèches there is scope for great development in these directions. The nursery proper should, if possible, face 
south and have large windows. Sunshine is not only cheering, it probably has other important effects on our well-being of which at present we have very little definite knowledge. An ordinary fire is by far the best way of heating the room. Gas stoves and even the most modern gas fires are very objectionable. It would seem scarcely necessary to mention the fire-guard were it not for the enormous number of deaths from fire that still occur amongst young children. There should be as little furniture as possible, simple, strong and free from sharp points and angles, and some baby chairs which the children can move about themselves. Keeping the toy cupboard tidy is one of the first steps in the child's education. Whenever anything is bought for the nursery you should consider first, is it easy to keep quite clean, secondly is it durable, and thirdly is it pleasing to the eye? The best thing for the floor is cork lino with one or two large washable rugs or mats; and for the walls, one of the various washable distempers. Whatever the other toys are there should always be a blackboard with chalks and plenty of large wooden blocks for building. 


\section{EXERCISE}

Most people know in a vague sort of way that exercise is good for the circulation, expands the lungs and keeps the liver in order.

But it does much more than this.

I. It is the chief source of the body heat.-If the child does not romp about because the clothes are too heavy or for any other reason, he does not lose so much heat, and does not form so much heat, and therefore the chemical activities of the body are not so great as they should be. In other words the child lacks vitality and vigour.

2. There are two fluids circulating in two distinct systems of tubes throughout the body. One is the blood which, as every one knows, is pumped through the blood-vessels by the heart. The other is the lymph which circulates through tubes known as the lymphatic vessels. The circulation of the lymph is of the greatest importance, and it is maintained entirely by the movements of the muscles, that is to say, by exercise.

3. The regularity of the bowels is affected directly and indirectly by exercise; directly 


\section{HYGIENE OF THE NURSERY 59}

by what has been described in the chapter on clothing as 'auto-massage,' and indirectly by maintaining the vigour of the abdominal muscles and by preventing the lethargy which derives from the accumulation of waste products in the muscles.

4. The development of the bones depends on the development of the muscles working them. Plenty of exercise means good firm muscles and a strong frame-work of bones. It is obvious that this is a good object to achieve; but its prime importance is only realised when one remembers that the most important part of the blood (the red blood cells)-is formed by the bone-marrow. Healthy blood depends amongst other things on healthy bones, healthy bones depend on healthy muscles, healthy muscles depend on freedom of the limbs and the opportunity of playing in the open air.

An infant should not be persuaded to stand or walk before it shows a desire to do so ; nor should it be discouraged, however early its first voluntary efforts are made.

It is very important to realise that a child never gets bent legs if it does not suffer 
from Rickets. So that there is never any need to check a healthy child from running about.

Hoops, spinning tops, skipping ropes and roller skates are excellent. So are tricycles and bicycles, but there is a great tendency for these, especially bicycles, to be used too much. Bicycling is a wholesome pastime, if the machine fits the child, the child sits up properly and is not persuaded to try and keep up with his elders. But in many cases it altogether replaces walking, and this is very undesirable. Walking is going out of fashion, but there is nothing better than a good long tramp in the country for people of all ages from five or six upwards. All healthy children should be taught to swim. All boys should be encouraged to become boy scouts. Mothers often wonder whether their boys are not overexerting themselves and getting too tired. The only danger of this is in the case of a boy competing (as in school sports, cross-country running and so forth) against boys who are older or stronger than himself. 
HYGIENE OF THE NURSERY 6I

\section{REST}

Nothing is more deleterious to a child than insufficient rest. Children are like the young of other animals-there is a natural alternation of periods of ebullient energy with periods of complete relaxation. The unwilling walk along paved streets between monotonous rows of villas is a terrible infliction on childhood. It is only in the playground or the garden that the child's natural energies are awakened. There he romps until he is healthily tired, and then he should be encouraged to rest.

Up to the age of seven, a child should lie down, preferably in the latter part of the morning for an hour or so. At all times he should be given the opportunity to rest when he feels disposed to.

At the approach of puberty, girls are apt to develop slight lateral curvature of the spine owing to weak back muscles being inadequate to bear the rapidly increasing weight of the breasts. This trouble is prevented by resting an hour or two during the day, and strengthening the muscles by outdoor games, skipping, dancing, etc. 


\section{FrESH AIR}

It must be clearly understood that fresh air means something more than clean air. Clean air is of the utmost importance. The air of a room in which a number of people have been present with closed windows smells foul and the effect of this smell is depressing; whether there are any poisonous gases present is still a matter of doubt. It has been abundantly proved that microbes may be air-borne; this is especially true of consumption. But there is something more than cleanliness that gives fresh air its peculiar value ; this factor appears to be that the air is in motion. Probably the minute currents and variations of temperature in the air as it strikes on the face have a bracing effect. But whatever the cause it is certain that pure stagnant air, that is to say, air which has been filtered, warmed and moistened, even though it may be moving in bulk, but in which there is no commotion, is very depressing. This explains the inadequacy of open doors to bedrooms in place of open windows. The air in the lobby may be pure enough but it is stagnant. The air out of 
HYGIENE OF THE NURSERY 63

doors is in constant motion. The fresh air treatment has acquired its reputation in connection with consumption. It is equally advantageous for other diseases. But it is when one has learnt that it is equally important for health that one has grasped its true significance. There are many degrees of health. A child is often poorly, languid, apathetic and so forth without being ill. For a child to be in first-rate health, 'the top of its form,' it must lead the fresh air life, day and night.

Insufficient warmth to the body is no part of the treatment. If a child is sleeping out on a balcony, it must have sufficient clothing and if necessary hot bottles to ensure its comfort.

On the other hand, great cold is no bar to this method of living. In the most extreme cold (in this country) the body can with due care be kept sufficiently warm. The air that is breathed is warmed in the nose before it reaches the lungs.

' Open windows' does not mean a gap of one inch at the top of the window and a blind and heavy curtain over it. 


\section{THE HEALTH OF THE CHILD}

\section{CHILL}

Every one knows that a chill is often followed by illness; the ordinary name for a very common disease, 'catching cold,' illustrates this. It is true that its frequency is exaggerated. This is because at the onset of fever it is usual to feel cold and shivery, and it is supposed from these sensations that the patient has been unduly exposed in some way. Nevertheless it is indisputable that to get soaked in the rain and then take a railway journey in your wet clothes, for example, is to court disaster. Now there is a great deal of mystery about this word chill, and it is worth while clearing up the matter. Many people think that doctors contradict themselves when they recommend fresh air and warn you against chills. The body temperature is maintained by a balance of heat production and heat loss. The heat is produced chiefly by the muscles (flesh). Living muscle even at rest is always in a state of slight contraction (tone). This tone is the source of heat when the body is at rest. When the heat loss increases, the tone increases to keep 


\section{HYGIENE OF THE NURSERY 65}

up the balance. We all recognize that we are braced up in cold weather and lax in hot weather. When the heat loss increases further the individual feels a desire to move about, to run about or swing his arms. If he cannot move about, then he shivers involuntarily. This variation of heat production, as required, depends on impulses coming to the nervecentres from all parts of the body.

There are two ways in which a chill is produced.

First: When the natural tendency to move about is forcibly checked, e.g. sitting still in wet clothes.

Secondly: When the balance is upset by one small area of the body being cold whilst the rest is warm, e.g. wet feet or sitting in a draught.

It has been proved that animals with wet feet lose their resistance to microbes which they ordinarily are able to resist. So the child with wet feet loses its powers of resisting the microbe which causes catarrh of the nose; in other words, it catches a cold.

The cure for a draught is not to shut the window but to open it wide. Then the draught 


\section{6}

\section{THE HEALTH OF THE CHILD}

is converted into a breeze, the whole body is affected by the altered atmospheric conditions and responds accordingly.

\section{Mouth Breathing ('Tonsils and Adenoids')}

The throat has four openings-the nose and mouth separated by the palate open into it in front, while below it is continuous with the wind-pipe and gullet. Tonsils and Adenoids are present in all children. It is only when they are unduly large that they obstruct the passage of air from the nose, through the throat, into the wind-pipe. The child is then compelled to keep its mouth open. It is still a much debated point whether the tonsils and adenoids serve any useful purpose. It is a mistake to assume because the use of an organ is not known that it has none. Nor is this proved even by the fact that its removal has no evident bad effect. Nevertheless the vast experience of the removal of tonsils and adenoids that has accumulated points quite unmistakably to the fact that where they are diseased or so enlarged as to cause serious obstruction to proper breathing, they are best dealt with by operative measures. 
Causes of enlargement.-We are much in the dark about this. It has often been suggested that our damp climate is a factor. Undoubtedly a fruitful cause is dental caries. The decayed teeth keep up a state of inflammation of the gums which in turn leads to a chronic catarrh of the throat.

Results of enlargement.

I. Under-developed nose.-The face of a child with severe nasal obstruction is readily recognized. The little muscles of the nose which keep the nostrils expanded and enable them to withstand the indraught from the lungs with each breath that is taken are never exercised and so the nose does not grow. A number of cavities in the skull open into the nose ; and when the latter is small and pinched, these cavities become unhealthy; hence there are frequent headaches and a feeling of languor and heaviness of the head which hinders the mental growth.

2. Under-developed jaw.-The mouth being always open, the jaw muscles and jaws do not grow properly, so that there is insufficient mastication of the food and crowded permanent teeth. 
68 THE HEALTH OF THE CHILD

3. Under-developed chest. - This is very serious. The muscles of the chest which are used in breathing have less resistance to work against, having to draw the air through the mouth instead of through the narrow passages of the nose. Hence arises a poor flat chest and round shoulders.

4. The air in the lungs has not been filtered, warmed and moistened by its passage through the nose.

5. The secretions at the back of the nose and throat stagnate and become a breeding ground for microbes. The child gets repeated sore throats, bronchial catarrh and enlarged glands in the neck.

\section{Prevention and Cure}

The 'comforter' will probably never be abolished, and its sins have often been considerably overstated. Nevertheless there can be no doubt that it is better to do without it, and if it is used in emergencies, it should never be left for long periods in the baby's mouth, and the utmost care should be exercised to keep it clean.

A mother should watch the baby when 
asleep. Often with an infant the mouth can be closed, and kept closed by propping the bed-clothes under it. The child must be encouraged to keep its mouth shut when awake. The teeth must be carefully watched (see p. 9). Breathing exercises should be a part of the routine discipline of every child. Breathing exercises are very simple. For instance, the child stands facing you with its arms straight out before it, palms together. The arms are slowly separated until they are in a line with the shoulders, whilst a long deep breath is taken in through the nose. The arms are then dropped to the sides while the breath is let out through the open mouth. Another method is as follows. The arms are straight down by the sides, palms backwards, mouth closed. The arms are slowly turned round (everted) so that the palms face forwards whilst a deep breath is taken through the nose. Then they are allowed to drop back again into the natural position while the breath is let out through the open mouth. The child should have nothing on the chest but a thin vest, so that the teacher can see that the chest is really filling with air. This can be further ascertained by the teacher 


\section{THE HEALTH OF THE CHILD}

placing the hands on the lower part of the chest.

The child should not be allowed to raise its shoulders while breathing in. The aim of breathing exercises is first to teach the child to breathe through its nose, and secondly to increase the mobility of the chest; in other words the difference in its size during breathing in and breathing out. It is important to note this, because it is sometimes mistakenly thought that these exercises aim at producing a big chest. The growth of the chest is the proper response to the more general exercises which a healthy child naturally takes. If nasal obstruction is present or the tonsils are causing trouble of any other sort, professional advice should not be delayed. Here it is sufficient to express the view that there are slight cases where syringing the nose, breathing exercises and other such measures are sufficient, and that there are many other cases in which operative measures offer the best chance for the child's proper development. 


\section{V \\ THE SICK CHILD}

WhEN TO SEND FOR THE DOCTOR

THE practice of trying in a book to teach 1 mothers all the symptoms and the proper treatment of grave diseases is a mistake. The sensitive mother is terrified at the horrible prospects which are opened up, and the sensible mother when the grave condition arises depends on her medical adviser. It is bad to send for the doctor for every slightest deviation from health; the human organism is a very complicated machine and one can scarcely expect it always to run quite smoothly, also a baby that is ill tends to right itself like a ship on a stormy sea. Further, experience will familiarize a mother with the aspects of many minor ailments, and the way to deal with them. But for the young mother it is better to send for the doctor too often than not often enough. There are very many conditions of which it is 
very difficult for the layman-and often for the doctor too-to say at first whether they are quite trivial or very serious. Such as, for instance, sudden stomach-ache, ear-ache, sore throat, a limp or high fever. And in many such cases, it is of great advantage to the doctor to see the child at the onset of the trouble. So that the following observations will only deal with those conditions which can be safely dealt with by the mother or which are so sudden that some treatment is called for before the doctor's arrival.

\section{The Motions}

A mother should always observe the motions of a child until it is of an age to tell her when it is constipated. Apart from this trouble, many a clue can be gained by the daily inspection; the presence of curds of milk, of undigested vegetable fibre, of mucus, of blood and of worms all tell their tale. Threadworms are like little bits of white thread wriggling about, and are always on the outside of the motion and therefore easily seen. Other sorts of worms are less common, and are so big as to present no difficulty. This is the only 
test whether a child has worms or not-to look for them. And their presence should never be neglected-the doctor should be summoned.

\section{The Throat}

The child's throat should be inspected occasionally. This has the double advantage of acquainting the mother with the throat's aspect in health and of teaching the child to show its throat without fear.

\section{THERMOMETER}

Every family should have a thermometer and know how to use it. Many women have a superstitious dread of this useful instrument. 'I should always be taking their temperatures and finding them too high,' they say. The true answer to this is that nothing could be more worth while. Some children have a tendency to develop a high temperature from a very slight cause. When the doctor is called in and finds the temperature high, it may be of the greatest value to him to learn that a similar temperature has often been recorded before, and the child has been quite well again on the following day. On the other 


\section{THE HEALTH OF THE CHILD}

hand it is a great comfort when a child seems unduly hot to take the temperature and find that it is normal. But if you use a thermometer, there are some important things to remember.

I. Always clean it thoroughly before returning it to its case.-This is the most important. Otherwise the case may become infected and disease may be conveyed to others.

2. Never clean it in hot water.

3. Always note that it is shaken down to below 'normal' ( $98.4^{\circ}$, where the little arrow is) before use.

4. Keep it in for double the length of time stated. It is best to use a half-minute thermometer and keep it in a minute.

5. In an infant take the temperature in the bowel, but remember that it is naturally about a degree higher here than in the groin or under the tongue.

6. A sub-normal temperature is never serious unless the child is obviously very ill.

7. Never confuse $100.2^{\circ}$ or $100.6^{\circ}$ for example with $102^{\circ}$ or $106^{\circ}$. This is a common mistake which leads to great confusion. 


\section{RASHES}

When a child develops a rash, and yet does not seem ill, it is often a difficult question whether it is necessary to send for a doctor. Here again you will undoubtedly in the long run have less cause for regret if you sometimes send for him unnecessarily. It is by no means uncommon for a mild case of Scarlet Fever to be missed, until the skin peels or some late complication arises. Then again with Chicken Pox and German Measles, it is quite common for the child's general health to be scarcely affected, and yet if the condition is not treated as an infectious one, an ext nsive epidemic may result. And if you send for the doctor, send at once, for the rash may quickly change in appearance or disappear. Remember that it is much easier to see the true nature of a rash by daylight than by artificial light. Yet it must be remembered that there are many other causes for ' spots' besides the infectious diseases. The rashes in infants associated with teething and indigestion are familiar to most of us. So is 'nettle-rash' produced sometimes by strawberries, shell-fish, 


\section{THE HEALTH OF THE CHILD}

etc. The bites of insects occasionally produce extensive and puzzling eruptions. A severe perspiration may be followed by what is known as a 'sweat-rash.' And mothers are often puzzled by a rash on the chest and back, arising from the use of a liniment such as camphorated oil on a sensitive skin. Generally speaking, if a rash is at the onset unaccompanied by any rise of temperature it is very unlikely to be the sign of an infectious disease.

\section{Cough ANd Croup}

Children often develop a slight cold on the chest for which it does not seem necessary to seek a doctor's advice but for which one feels one would like to do something. One has given glycerine and black-currant lozenges and rubbed the chest with camphorated oil and still this little cough persists. Do not have recourse to somebody's lung tonic or somebody else's lightning cough cure. Most patent medicines may be divided into three classes.

I. Those whose sole virtue lies in the amount of capital they can sink in advertising.

2. Those whose virtue lies in their aperient 
action (and this is true of one very well-known preparation for coughs).

3. Those which have some sedative action which allays the symptoms but does not cure the condition.

The third class is the dangerous one, because it means that the disease has time to establish itself before the doctor is sought for.

I pecacuanha wine is however a perfectly safe household remedy if used properly. It may be used in two ways. The best is to give from two to six drops, according to the child's age, four times a day in a little water. If the cough is not better in a few days, send for the doctor (and tell him exactly what has been done). The other way is to use it as an emetic, giving a teaspoonful every quarter of an hour until the child is sick. Whilst vomiting it often expectorates a quantity of phlegm. This treatment is not to be recommended except on the doctor's advice.

Croup is a name which has been used for a variety of conditions, including Diphtheria, catarrh of the upper part of the wind-pipe (laryngitis) and a peculiar spasmodic condition of this part which occurs in rickety infants 


\section{THE HEALTH OF THE CHILD}

from six to eighteen months. But it is properly used for an obstruction of the breathing which occurs in children from 2 to 6 years of age. The child goes to bed quite well or with perhaps a slight cold and sometimes between Io P.M. and 2 A.M. wakes with a hard brassy cough, takes its breath in with great difficulty and with a loud crowing noise, is obviously very distressed, and may become blue about the cheeks and lips to an alarming degree. The trouble often recurs for some nights in succession. As has been said, the appearance is very alarming but the condition is never fatal. After one or two hours, the attack subsides, "the child falls asleep exhausted and wakes next morning quite well' (Still). The immediate treatment is to moisten the air with steam from a kettle and to apply heat to the front of the neck, either a hot sponge or a small mustard poultice.

\section{PAIN}

It must be understood that when some part of the body is disordered, the place where the pain is felt may be far away from the seat of trouble. Thus in hip disease, the child usually 


\section{THE SICK CHILD}

says its knee hurts; pain in the stomach may be due to trouble in the chest or in the backbone; ear-ache may be due to a bad tooth and a teething child will often be seen to pull its ears. A point worth remembering is that ordinary 'stomach-ache' is relieved by light pressure or gentle rubbing; if the pressure increases the pain it is a sure sign that the doctor should be sent for.

Warmth always relieves pain and is quite safe treatment while you are waiting for the doctor ; a hot shawl, a hot-water-bottle, a hot sand or salt bag, a poultice or a hot compress (see p. 86). These are the best means of relieving pain whether in the head, the chest, the stomach or the limbs.

\section{Convulsions}

Very often a child is very nervous, starts at the least sound and twitches in its sleep before a convulsion occurs. At this stage a doctor can often prevent the attack; short of a doctor, the best thing is a good dose of castor oil. When the child is in convulsions, the best treatment is to immerse its body for a few minutes in a bath of water that is distinctly 
8o THE HEALTH OF THE CHILD

hot, though quite comfortable to the elbow and sponge the head with cold water. Then lay it in bed, wrapped in a blanket, and await the doctor's arrival.

\section{BeD-WetTING}

Never punish the child for the habit. Let his life be calm and free from excitements. See that he does not suffer from worms (see p. 72), that he does not require circumcision, and that he is not constipated. Encourage him to drink plenty during the day, but give him the lightest possible supper or none at all. Wake him up when you retire. It is a very troublesome habit which is sooner or later ' grown out of.' Sometimes medicinal treatment is useful.

\section{INFLAMMATION OF THE EAR}

It is often necessary to impress upon mothers that 'running ears' constitute a very serious complaint and require medical care. The lack of such treatment often causes permanent deafness and may lead to fatal complications. 


\section{The Eyes; Bad Habits; Nervous}

CHILDREN

Of the special senses, hearing, smelling and tasting are very seldom defective from birth in children, but unfortunately there is often some defect in sight which, if not properly treated, may give rise to a variety of troubles. A mother was once very much annoyed because her child, having a crooked back, was sent to a hospital, and was returned with a pair of spectacles. The trouble with the back had come from faulty sitting at school owing to shortsight. A child with a squint should never be left without expert advice. Headaches are often due to eye-strain. So are red eyelids and styes. A habit of blinking the eyes may be due to the same cause.or it may be a nervous habit.

Bad habits. - When a bad habit appears, one should ask oneself-Is it due to some quite extraneous cause such as mimicking an older child, is it due to some central lack of nervous control, or is it due to some local trouble which can be remedied? The local cause may often be removed by, for example, spectacles for 


\section{THE HEALTH OF THE CHILD}

defective vision, the removal of adenoids or appropriate treatment for intestinal worms. If the bad habit be due to central lack of nervous control, the treatment lies rather in the exercise of more than usually strict discipline coupled with more than usual care to avoid punishments-rewards for improvement are much more efficacious. By discipline is meant encouraging the child in all its daily occupations to practise self-control, always, for instance, to finish what it begins doing, and never to try to do two things at once.

A 'nervous child' should have a life not deficient in interest but on the other hand not too exciting. It should mix freely with other children but should avoid parties. Everything should be done in the way of plain wholesome food and out-of-door life and early bedtime to improve the bodily health. Although discipline is more than usually important it should not be too Spartan. Most children, properly trained, have no fear of sleeping in the dark. But to some of them the dark is full of terrors, and such should be provided with a night-light.

Children can suffer horribly in the hands of 
unimaginative adults. I know a lady who recalls with loathing the agony that she endured as a little girl from being made to wear flannel next her skin. No complaint of a child should lightly be dismissed as a fad, until one has assured oneself that it does not carry with it other unpleasant association in the child's mind and that it is not the expression of some quite genuine idiosyncrasy.

\section{Home NuRsing}

It is very difficult to persuade mothers of the importance of keeping the child in bed when it is out of sorts. Often the difficulty is that the mother cannot be in the kitchen and bedroom at the same time. Usually the bed can be put in a cool corner of the kitchen. Constant dandling in the mother's arms is wearying to the child, and though the mother has the satisfaction of feeling that she is doing something, she also gets needlessly exhausted. Kept in bed, the child may have a good cry at first, but will then settle down. The great advantage is that it is then in a position to drop off to sleep at any moment, and may 


\section{THE HEALTH OF THE CHILD}

then remain asleep for a long time to its great benefit.

Some brief hints for nursing in the sick-room may be useful.

Quiet is important-quiet shoes and quiet manners, and especially the avoidance of sudden noises. The coals are not shovelled on, but handled with the help of an old glove and the doors are not banged. On the other hand, whispering and tip-toe walking are extremely trying to the patient.

Health of the Nurse.-In the case of a long illness, it is bad policy for a mother to martyr herself for the sake of the child. Good health is essential to good nursing. Daily outdoor exercise, a daily uninterrupted and adequate spell of rest, and proper regular meals are essential.

\section{Common-Sense Rules}

Measure quantities rather than guess at them, e.g. sleep.

Tell the doctor everything. The most important thing is apt to come last.

Aim at precision.-Mothers are wont to say 
that a child has had some symptom for ' some time.'

Keep anything strange vomited or passed.

Don't fuss.-Remember that both you and the doctor are only fallible and that you can both only do your best.

Don't try treatments of your own (usually your friends') simultaneously with the doctor's treatment.

Food.-Nagging will never make a child who is ill eat more, but it makes a great difference whether the food is presented in a palatable form or not. Every mother should know something of cooking if only to help her to detect what is wrong in the discarded dish. Invalid food often requires special care. Benger's Food is an obvious example, and peptonized milk is horrid if it is not properly prepared.

It is well to remember that in the case of fever no meat extract-such as is found in stock soup, beef tea and Bovril-should be given. These should be reserved for the convalescent period succeeding the fever. The importance of always giving a child as much water as it will drink has already been dealt with (p. 44). 
$A$ fire in a sickroom is nearly always worth while. It is cheerful, it helps to keep the air moving, and it is useful for burning odd bits and warming things.

The Bed. Never have the child's bed facing the window.-It usually does. The child gets a headache from having the light in its eyes all day, and in the case of an older child, the printed page of its book is in the dark. The bed should be placed sideways, so that the child can see out if it wishes. To have nothing but a wall to stare at all day is trying.

The mattress of every child's bed, well or ill, should be rather hard. A feverish child often has more instead of fewer bed-clothes on it. It must be completely but quite lightly covered. It is scarcely ever dangerous for a small child whatever its illness to sit up if it wants to, provided that it is properly covered.

\section{Things THE DOCTOR WILl WANT TO KNOW}

What is the favourite attitude of the child? Are these flushes, twitchings, perspiration?

Pain.-In the case of an infant does it put its hand to any part as though in pain or pull its legs up? In the case of an older child is 
the pain constant or intermittent ? Relieved or increased by pressure? Fixed at one spot or shooting in some direction?

The tongue.-Has it been furred or clean; dry or moist?

The cry.-Is it loud, which means that the child is strong and has clear lungs? Is it constant, which always means that the child is in pain?

Sickness.-Is this only nausea or does the child actually vomit? If so, what does it bring up. How has the appetite been ?

The urine.-Its colour, quantity, consistency. A feverish child nearly always passes urine which, on standing, has a thick reddish deposit. This often causes unnecessary alarm.

These are but samples; everything out of the normal should be reported.

Things the Doctor May Order

Fomentations (Hot Compresses). - Fold a piece of flannel to make a pad of four layers. Place it in a hand towel, lightly twist the ends of the towel and place in a basin with the ends of the towel hanging out. Pour on boiling water. Twist the towels tightly to 


\section{THE HEALTH OF THE CHILD}

squeeze out as much water as is possible. Apply the flannel pad and cover with a piece of waterproof such as oil-silk or jackinet.

The important points are :

I. The water should be actually boiling.

2. The better it is squeezed, the hotter it can be applied.

3. The waterproof should overlap the edge of the flannel all round.

4. The waterproof should be placed handily, so that it can be clapped over the instant the flannel is applied.

5. The patient should not be burnt. It is a good plan to put your hand between the skin of the patient and the flannel at the moment of application, and gradually withdraw it.

Instead of water, an antiseptic solution may be used. Fomentations are more handy and cleaner than poultices but do not keep the heat so long.

Poultices.-The most useful are linseed, mustard and bread.

The linseed poultice.-A little practice is worth a great deal of description. The chief thing to remember is that everything should be very hot. The linseed may be stirred 
into the boiling water, or the water poured into the linseed. The mixture is stirred with a spoon, previously heated, until it is semi-solid. It is then spread on a square of old linen, to form a layer a quarter of an inch to half an inch thick, the edges of the linen are turned over and the linseed is applied direct to the skin with nothing intervening.

The mustard poultice is made the same way, except that about one part of mustard is added to four parts of linseed.

The bread poultice is made by stirring the crumbs of stale bread into boiling water, and keeping the whole hot for five minutes to allow the bread to swell.

Poultices should never be applied to an open sore, such as a discharging whitlow, because, from the surgical form of view, they are dirty.

Boracic Acid lotion.-A heaped teaspoonful of Boracic Acid crystals may be dissolved in a breakfast cup of warm water. Another useful plan is to keep a large bottle of 'saturated ' solution (i.e. water to which Boracic Acid has been added until some remains undissolved) and when lotion is required, to $\mathrm{mix}$ 


\section{THE HEALTH OF THE CHILD}

some of this with an equal quantity of hot water.

Albumen Water.-Take the white of one fresh egg, divide it in several directions with a pair of clean scissors, then mix it with eight ounces of cold water in a bottle, and shake vigorously; strain through muslin.

Beef Juice.-One pound of finely chopped rump steak, six ounces of cold water, a pinch of salt; place in a covered jar and stand six hours. Strain and squeeze the juice out by putting the meat in coarse muslin and twisting it very hard. Warm by placing the cup in hot water.

Beef-Tea.-One pound of finely chopped lean beef, one pint of cold water, a pinch of salt. Cook for three hours over a slow fire down to half a pint, adding water if necessary. Strain through muslin and when cold carefully remove the fat.

There are various ways of making beef-tea. The method described gives a product which is more stimulating than nourishing. If flakes of beef are left in, the result, though not so easy to digest, is much more of a food.

Whey.-One pint of milk warmed; a pinch 
of salt; a teaspoonful of sugar. Add two teaspoonfuls of liquid rennet, stir, and allow to stand for twenty minutes. Break up the curd and strain through muslin.

Things to have in the Medicine Chest.-A few roller Bandages, Cotton wool, boracic Lint, Boracic Acid crystals, some antiseptic such as Cyllin, Castor oil, Ipecacuanha wine, Camphorated oil, Glycerine, 'New Skin,' a reel of Zinc-oxide Strapping, $\frac{1}{2}$ inch width, Carron oil with Io per cent. Eucalyptus oil (v. Burns), Oiled silk, boracic Vaseline, a Glycerine Syringe.

\section{Measures}

2 Teaspoonfuls $=\mathrm{a}$ Dessertspoonful,

2 Dessertspoonfuls=a Tablespoonful,

2 Tablespoonfuls $=$ an Ounce.

20 Ounces $=$ a Pint.

It is often said that a teaspoonful equals a drachm, but in point of fact the ordinary teaspoon holds nearly two drachms. A tumbler holds just under half a pint.

Common Infectious Diseases of Childhood

An infectious disease is one that spreads from one person to another. All infectious 


\section{THE HEALTH OF THE CHILD}

diseases are probably caused by some microbe (or germ). The infectious diseases common in childhood are Measles, German Measles, Scarlet Fever, Chicken Pox, Whooping Cough, Mumps and Diphtheria. It is an unfortunate thing that so far in the case of none of these diseases except the last mentioned (Diphtheria) has the offending microbe been found. A very infectious disease, common to all ages, is the ordinary cold in the head. There is a considerable amount of evidence to show that a cold in the head is never contracted except by infection from another person. Therefore any one who has a cold should be most careful to hold a handkerchief to his face when he coughs or sneezes, to keep his room thoroughly ventilated and to avoid kissing others. In fact it should be a universal rule never to kiss any one outside your own family. Some infectious diseases produce what is called immunity. That means that having once passed through an attack one is not likely to get the complaint again. The amount of immunity varies with different diseases but of no disease can it be said to be impossible to have a second attack. Other infectious diseases like a cold or influenza 
produce no immunity whatever or one that passes off very quickly.

After a child has been exposed to infection, some time passes before he shows any sign of being ill ; this is called the period of incubation. This varies in duration, and while it lasts he must be kept away from other children. So that we have the average period of incubation which gives the date at which he is likely to become ill and the longest possible period of incubation which gives the date at which, if he is still quite well, he may be considered safe.

Average Period of Incubation.

Chicken Pox Measles

German Measles Whooping Cough Scarlet Fever

Diphtheria Mumps
I4 days

9

)

2-7 days very variable

2-3 weeks
Quarantine Period. 2 I days

"
I4 days
24 days.

The onset of these diseases will now be described very briefly; in every doubtful case it is safer to consult a doctor.

Mcasles.-For a few days, the child seems 


\section{THE HEALTH OF THE CHILD}

out of sorts; he has a little cough, sneezes occasionally and complains that his eyes hurt him. After three or four days he becomes distinctly feverish and spots, the size of a pea, appear all over him, including the face.

German Measles is quite a separate disease, though very similar. There are generally few obvious signs except the rash and a slight rise of temperature at the onset.

Scarlet Fever.-The onset is very sudden with a high temperature, sore throat and headache. Often the child vomits. The rash consists of spots, smaller than pin's head and so close that often the appearance is that of a red blush over the chest. It usually appears within twenty-four hours of the onset of the disease. Although the cheeks are flushed, there is no rash on the face.

Chicken Pox.-The child is seldom very ill. Often the rash first calls attention to the condition. The spots are scattered all over the body, the scalp and the palate. Some are little pimples and others are blisters like drops of water on the skin.

Diphtheria.-The temperature is seldom very high, although often the child looks very ill. 
The glands of the neck, on one side or both are swollen and there is a white patch on one or both tonsils. Little white pin-points on the tonsils usually mean simple tonsillitis (not Diphtheria). The early use of antitoxin is so important that not an hour should be lost, in the case of a suspect, in applying to the doctor.

Whooping Cough.-There is an ordinary cough for a week or ten days. Then the intervals between the attacks of coughing become longer and each attack consists of a series of little coughs ending by a long, noisy in-drawing of the breath which constitutes the whoop. The cough is often so severe that the child dreads the approach of each paroxysm, the face becomes congested and the food may be vomited. Very often the cough is worse at night. This is the only disease in which a child spits out the phlegm.

Mumps.-Mumps is often difficult to distinguish from enlarged glands of the neck, but the swelling, in the former, spreads over the angle of the jaws on to the face in front of the ear. With enlarged glands, the swelling is strictly confined to the neck. With Mumps there is usually discomfort on opening the mouth. 


\section{THE HEALTH OF THE CHILD}

No child should ever be exposed to infection if it can be avoided. It is often tempting, with a large family, to aim at their all getting over it at once, but it has to be remembered that the mildest disease occasionally assumes a very grave form.

One word as to the mortality of Measles and Whooping Cough. A great many children die from these diseases and most of these deaths could have been prevented. Insufficient care while the child is convalescing leads to 'a chill' and some serious complication ensues. Amongst the uneducated some acquaintance with these risks would prevent many tragedies.

\section{EMERGENCIES}

\section{FOREIGN BODIES}

I. Swallowed.-Never give the child opening medicine. Give gruel, porridge or bread and milk, and strain the stools through muslin until the object is recovered.

2. In the ear.-If there is the least difficulty, leave it alone until you get a doctor.

3. In the nose.-Get the child to blow with 


\section{THE SICK CHILD}

the other nostril closed. Or syringe up the clear nostril.

4. In the throat.-If the child is choking, try to remove the object with your fingers. If you can't, hold the child up by the feet, head downwards.

5. In the eye.-If you cannot get it out with a clean handkerchief or by lifting the upper lid over the lower, bathe with warm boracic lotion squeezed out of a piece of clean cotton wool. If this fails, send for the doctor.

Burns. - The best applications to keep in the house for burns are (I) a I per cent. solution of Picric Acid, (2) Carron oil with ro per cent. Eucalyptus Oil added. For quite slight burns, flour or salad oil are of use.

The danger of a bad burn is proportional to the extent of surface involved, not to the depth. It is worse on the trunk than on the limbs. Death is either immediate, due to shock or, later on, due to blood poisoning. Therefore with a bad burn the great thing, as in so many emergencies, is not what to do but what not to do. Do not attempt to remove the clothes and do not put on any grease unless it is antiseptic. Keep the 


\section{THE HEALTH OF THE CHILD}

child very warm and quiet until the doctor comes.

Wounds.-Bleeding from a wound usually looks worse than it is. The great things to remember are to apply pressure directly on the bleeding spot, to keep the patient lying down, and if the wound is on the arm or leg, to raise the limb. For further details you must consult a book on First Aid.

An antiseptic such as Lysoform or Jeye's Fluid should always be kept in the house. A wound should be thoroughly washed with a lather of soap and water, and then a piece of clean lint which has been dipped in the antiseptic (a tea-spoonful to the pint of hot water) should be bound over it.

Dog bites are in England no more dangerous than any other wound which may be dirty, and should be treated in the same way.

Hydrophobia is stamped out in England.

Nose-Bleeding.-The child should lie flat on its back with its head turned to one side, and it should be provided with a soap-dish into which to spit the blood as it collects in the throat. If it keeps quite still, the bleeding will nearly always soon stop. 
Bruises.-Very little can or need be done. Lead lotion is a soothing application, or the treatment adopted in the case of Jack and Jill may be followed.

Concussion.-A child's head is very elastic and can sustain with impunity many a nasty blow. But if a child after a fall on the head appears drowsy and vomits, it is better to consult a doctor.

Fractures and Dislocations. - In a suspected case, do nothing but support the limb until the arrival of the doctor.

Poisons.-If a child has swallowed something poisonous it must be made to vomit either by putting a finger down its throat or by giving it an emetic. The best emetic is Ipecacuanha wine, a teaspoonful in a little water, every ten minutes, until vomiting occurs. Usually two doses will prove sufficient.

An emetic should not be given if

I. A caustic poison has been swallowed. There will be sore congested patches about the lips and mouth and great pain in the chest and stomach. If the poison is known to be an acid, give Baking Soda in water; if it is an alkali (such as caustic soda) give weak vinegar or lemon juice. 


\section{IOO THE HEALTH OF THE CHILD}

2. The child has already vomited effectually.

3. The child is extremely collapsed.

4. The length of time that has elapsed makes it certain that none of the poison remains in the stomach.

It is always safe (except in the rare case of Phosphorus poisoning) to give milk and raw eggs beaten up.

In any case of severe collapse, it is important to keep the child quiet, lying down flat and warm. 


\section{V1}

\section{TRAINING THE CHILD}

T the training of a child, the character with 1 which he is born and the characters of those who care for him are the things that count. As far as the child is concerned, the stuff that is in him is much more important than the method used for bringing it out. For systems of Education come and go. Each one, as it comes to hold the field, occasions some searching of soul amongst those who have been using other systems, until it in turn gives way to something yet more up-to-date. And to all of them there is one thing in common. Their success has depended far more on the personalities of their founders than on any intrinsic features of the method. This is not to say that one's method of training is without importance ; but it is a source of some consolation to an anxious parent perplexed by many rival claims. It encourages one to keep an open 
mind. Our ideas of education are still extremely inchoate. The words of Stevenson have their application. "We must not be pontiffs holding doctrines but huntsmen questing after elements of truth.'

Only second in importance to the personality of the child is the personality of its guardian. From which it follows that parents must try to be worthy of their children. A child cannot choose its parents; but parents can choose to alter their way of living for the sake of their children. The Japanese have put something of the force of religion into their reverence for their ancestors, with great resulting benefit to their race. But there is something yet nobler in the ideal which consecrates one's life not to those who have gone but to those who are yet to come.

It is obvious that the parents must be prepared to devote time to their children. Especially is this true of the mother. However admirable her personality, it is of little avail, if a nurse acts as a complete barrier between her and the child. A nurse is often a necessity; but it is always a regrettable necessity. Nothing is more valuable to a child than 
that familiarity with its mother which is only begotten of constant companionship and which makes him realise that in her he has a refuge in all his trials and troubles.

Invaluable as this knowledge is from infancy to adolescence, yet from infancy too a child must learn that his mother cannot be always with him. Training begins from the first week of life. Nothing is more remarkable than the facility with which an infant acquires habits. It learns from the first week to require its food at regular intervals, to go to sleep when replaced in its cot and to do its duty when it is ' held out.' If it cries when the mother leaves it, it must be allowed to cry. The ideal usually held out to the young mother is to let it cry until it stops. This is an excellent ideal; a healthy child, crying only from vexation, may get very exhausted, but it never does itself any serious harm. In practice, it is a very difficult ideal to live up to; one can only do one's best.

This naturally leads us to the difficult question of punishments, a question on which it behoves all of us to speak with great diffidence. If kindness is tempered by firmness, 


\section{I04 THE HEALTH OF THE CHILD}

punishment is reduced to a minimum. Nevertheless it has its proper place. The first thing to remember here, as always, is that no two children can be treated alike.

With regard to corporal punishment especially, there are as many opinions as there are teachers. I can only state my own. Between the ages of two and four years, a child is old enough to connect the punishment with the offence, but is not old enough to be amenable 1.) argument. During this period, a smacking applied very rarely and with great ceremony 'carefully and prayerfully' is, for some children, entirely beneficial. Later on, when a child defies authority, some deprivation or a short spell of meditation in bed is all that is required. Smacking, it must be repeated, should be sufficiently rare to be an event, it should be applied with great deliberation, and above all things, a child should never be casually hit on the head.

In reality, if a mother is only consistent and always means what she says, the habit of obedience is readily acquired. And if it is not, what is the alternative? The child is spoilt. It is astonishing that this profoundly significant 
phrase-spoiling a child-is used so casually. Few of us wilfully spoil our best valued possessions. But a good many people quite wilfully spoil the human beings whom they have brought into the world. If one pauses to think one cannot but realise its gravity. Direct cruelty to a child is abhorrent to us all. Yet the cruelty of spoiling a child, though indirect, is none the less real. There is an impression that a spoilt child improves as it grows older. This is true and it is equally true that a child that has been treated with direct cruelty will often seem to throw off the effects later. But nothing can undo the evil. And it is abundantly evident to the observant that the spoiling of a child can never be undonethat something of the fineness of its character is gone permanently.

Spoiling is often due to excessive anxiety, which leads to coddling the child. Ruskin, in Praterita, regrets that 'his character was innocent by protection, not virtuous by practice.' The burnt child minds the fire; that is what Ruskin means by being virtuous by practice. But one can go too far in the hardening process and incur unwarranted risks. 


\section{Io6 THE HEALTH OF THE CHILD}

One must bear in mind that the child may be dangerously burnt. One sees, for instance, children whose parents are eager to harden them, insufficiently clothed, unsuitably fed and allowed to forgather with unsuitable companions. But one sees far oftener the child who is so over-clothed that it does not care to run and climb, so pestered about its food that the relish of it has gone, and so hedged about, that it has no companions at all, desirable or otherwise.

The young child should have all the freedom it can get; freedom to roam, freedom to dream and freedom to get into a mess. Only too soon comes the drudgery of school and all the machinery for producing an efficient citizen. It is impossible to lay down rules as to when lessons should begin. John Stuart Mill studied the classics in his infancy and apparently throve on it ; but for most children one is safe to say that while they are happy all day, running wild and playing, there is no hurry to begin lessons. It is when time hangs heavy on the child's hands that the value of a short daily lesson becomes apparent. And it will be found that ' the only child' suffers less from 


\section{TRAINING THE CHILD}

its unfortunate situation if it is sent early to school. As the child grows older, school demands more and more of it. These demands are legitimate. But it must never be forgotten that the healthy mind demands a healthy body. 



\section{N D E X}

ADENoIDS, 10, 66-70.

Air, fresh, 62.

Albumin water, 49,90 .

Allenbury bottles, 24 .

Anaemia, 10, 59.

Ante-natal conditions, 3, 14, 16.

Antiseptics, 89, 91, 98.

Aperients, 15, 46, 47, 48 .

Apples, 39, 40.

Auto-massage, 55, 59.

Aymard's sterilizer, 30 .

BAcon fat, 43.

Bananas, 40.

Barley water, 29.

Bathing, 52, 53 .

Beds, 86.

Bed wetting, 44,80 .

Beef dripping, 43.

— juice, 90 .

Belts, 54.

Bent legs, 59.

Bicycles, 60.

Binders, 5, 54.

Biscuits, 43.

Bites, of dogs, 98 .

$$
\text { of insects, } 76 \text {. }
$$

Bleeding, 98 .

Body temperature, 3 .

Boiled milk, jo.

Bolting food, 44 .

Bones, development of, 10, 59 .

Boracic acid lotion, 89.

Bottles, 24.

Bowels, regularity of, $45-48$.
Boy scouts, 60.

Breast-feeding, 17-24.

Breathing exercises, 69, 70.

Bronchial catarrh, 68 .

Bronchitis and teething, 9.

Bruises, 99.

Burns, 97.

Butter, 43.

Calomei, 47.

Caries of teeth, $9 \cdot 13$.

Casein, 18.

Castor oil, 46, 47.

Catarrh of the nose, 64 .

Cereal foods, 38 .

Chicken pox, 94 .

Chills, 64, 66, 96 .

Chocolate, 12.

Choking, 97.

Circumcision, 80.

Cleanliness, r, Ir, 19, 24, 5 I.

Clothing, 54-56.

Cold catching, 64. baths, 53 . meat, 44 .

Colic, 4I, 45.

Comforters, 68.

Concussion, 99.

Constipation, 45-48.

Convulsions, 79 .

Cough, 76.

Cow's milk, 19.

Cream, 29, 34 .

Croup, 77.

Crying, 21, 87.

Curd indigestion, 28. 


\section{IIO THE HEALTH OF THE CHILD}

DECAYED teeth, 9.

Diarrhoea, 48-50.

Diets, I I, 37-45.

Dinneford's magnesia, 46.

Diphtheria, 94.

Dirty milk, 24, 30 .

Dislocations, 99 .

EAR trouble, 80,96 .

Emetics, 77.

Enemas, 47.

Exercise, 58-60.

Eyes, defective, 8I.

- foreign body in, 96 .

FAT, 43.

Faults of hand feeding, 30-34.

Feeding bottles, 24 .

Fever, $73,85,87$.

Fire guards, 57 .

Fires, 57, 86.

Flatulence, 33,45 .

Flies, 49.

Fomentations, 87.

Foot gear. 56 .

Fractures, 99.

Fresh air, 62, 63.

Furniture, 57.

GaS stoves, 57 .

German measles, 94.

Glands, 9, 68, 95.

Goat's milk, 18.

HABITS, 8r.

Hand-feeding, 19-22, 24-34.

Headache, ro.

Hip disease, 78 .

Home-nursing, 83-9r.

INCUBATION period, 93.

Indigestion, 10-28.

Infectious diseases, $9 \mathrm{r}$.

Invalid feeding, 85, 90.

Ipecacuanha, 77, 99 .

LACT-ALBUMIN, I8.
Laryngitis, 77.

Lime water, 29.

Liquorice powder, 48.

'Little folks' bottles, 24 .

Lymph, 58 .

MAGNESIA, 46.

Malted rusks, 37 .

Manna, 46.

Maternal impressions, $\mathbf{1 6}$.

Measles, 93.

Measures, 9r.

Medicine chest, 9r.

Menstruation, 8, 22.

Microbes, 1, 2, 4, 92.

Milk constituents, 18 .

- dirty, 24.

- goat's, 18.

— Pasteurizing, 30.

sugar, 29.

Motions, 28, 4I, 72.

Mumps, 95.

NAPKINS, 51, 52, 55 .

Nervous children, 82 .

Nose-bleeding, 98.

foreign body in, 96 .

Nursery milk, 25.

Nursing, 83-9r.

Olive oil, 46.

Orange juice, 37,46 .

PAIN, Io, 78, 86.

Paraffin, $15,46,48,54$.

Patent foods, 33-37.

- medicines, 76 .

Poisons, 99.

Porridge, $39,40$.

Poultices, 79, 88, 89.

Punishments, 103, 10.4.

RASHES, 9, 75, 76.

Resting, 6r.

Rickets, 33, 35, 59, 60.

Robb's biscuits, 37 .

Rupture, 55 . 
SCARLET fever, 94.

School, ro6.

Scurf, 54 .

Scurvy, 36.

Senna, 48.

Shoes, 56.

Skin, care of, $5 \mathrm{I}$.

Soap, 52.

Sodium citrate, 28.

Sore throat, xo, 73, 95 .

Soxhlet apparatus, 30 .

Spinal curvature, 6r.

Starch, 43 .

Stockings, 56 .

Stomach ache, 79.

Sweat rash, 76 .

Sweets, 12.

Swimming, 60 .
TEA, 44 .

Teeth, 8-1 3.

Thermometer, 73.

Thread worms, 72 .

Thrush, 53.

Tonsils, 10, 66-70.

Toys, 57.

Tuberculosis, 9, 31, 32 .

VoMITING, 6, 49, 77 .

WATER, 44 .

Weight, average, 8.

Wet feet, 65 .

Whey, 90.

Whooping cough, 9 .

Worms, 72, 80 . 
Printed by T. and A. Constable, Printers to His Majesty at the Edinburgh University Press 

THIS BOOK IS DUE ON THE LAST DATE STAMPED BELOW

AN INITIAL FINE OF 25 CENTS WILL BE ASSESSED FOR FAILURE TO RETURN THIS BOOK ON THE DATE DUE. THE PENALTY WILL INCREASE TO 50 CENTS ON THE FOURTH DAY AND TO $\$ 1.00$ ON THE SEVENTH DAY OVERDUE.

\begin{tabular}{l|l|l|}
\hline \hline Wifi. 291935 & \\
\hline & & \\
\hline & & \\
\hline & & \\
\hline & & \\
\hline
\end{tabular}




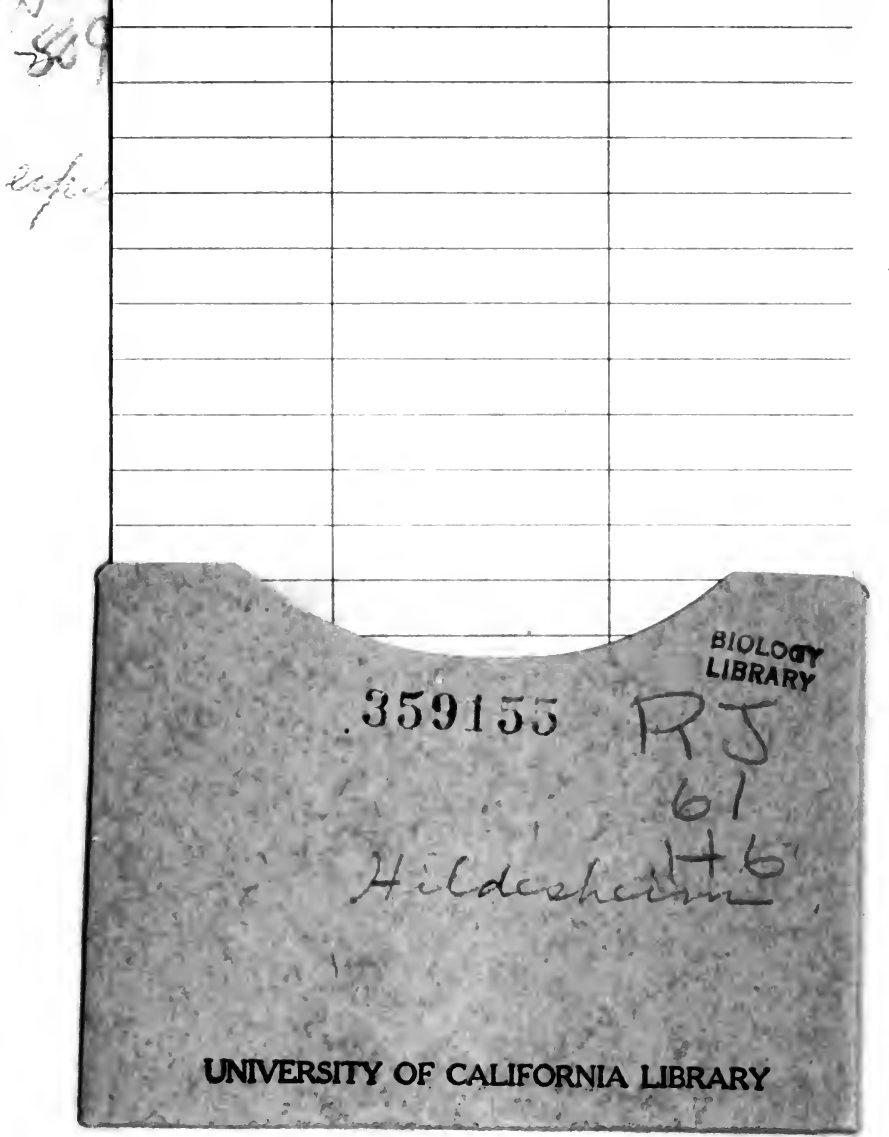


the

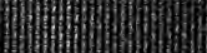

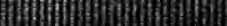

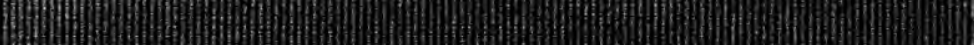

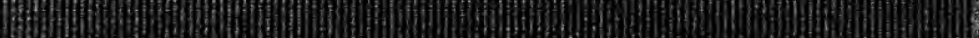

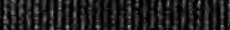

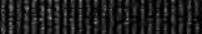
If:

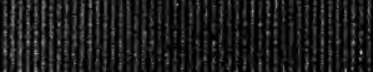

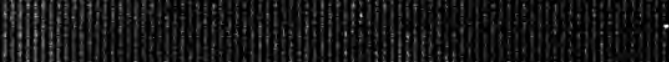

(1)

If(-

H(t)

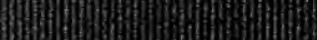

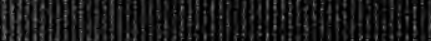

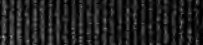

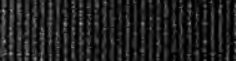

(f)

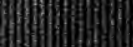

If

13:

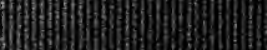

If

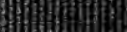

(1)

(1)

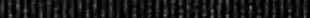

in|

(f)

(f)

If

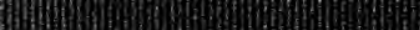

H(1)

Hin:

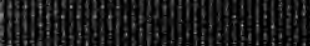

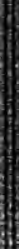

floth

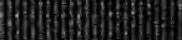

a) 